\title{
Upper-Ocean Thermal Structure and the Western North Pacific Category 5 Typhoons. Part I: Ocean Features and the Category 5 Typhoons' Intensification
}

\author{
I.-I. Lin, Chun-Chieh Wu, And Iam-Fei Pun \\ Department of Atmospheric Sciences, National Taiwan University, Taipei, Taiwan \\ DONG-SHAN Ko \\ Naval Research Laboratory, Stennis Space Center, Mississippi
}

(Manuscript received 6 June 2007, in final form 9 December 2007)

\begin{abstract}
Category 5 cyclones are the most intense and devastating cyclones on earth. With increasing observations of category 5 cyclones, such as Hurricane Katrina (2005), Rita (2005), Mitch (1998), and Supertyphoon Maemi (2003) found to intensify on warm ocean features (i.e., regions of positive sea surface height anomalies detected by satellite altimeters), there is great interest in investigating the role ocean features play in the intensification of category 5 cyclones. Based on $13 \mathrm{yr}$ of satellite altimetry data, in situ and climatological upper-ocean thermal structure data, best-track typhoon data of the U.S. Joint Typhoon Warning Center, together with an ocean mixed layer model, 30 western North Pacific category 5 typhoons that occurred during the typhoon season from 1993 to 2005 are systematically examined in this study.

Two different types of situations are found. The first type is the situation found in the western North Pacific south eddy zone (SEZ; $\left.21^{\circ}-26^{\circ} \mathrm{N}, 127^{\circ}-170^{\circ} \mathrm{E}\right)$ and the Kuroshio $\left(21^{\circ}-30^{\circ} \mathrm{N}, 127^{\circ}-170^{\circ} \mathrm{E}\right)$ region. In these regions, the background climatological warm layer is relatively shallow (typically the depth of the $26^{\circ} \mathrm{C}$ isotherm is around $60 \mathrm{~m}$ and the upper-ocean heat content is $\sim 50 \mathrm{~kJ} \mathrm{~cm}^{-2}$ ). Therefore passing over positive features is critical to meet the ocean's part of necessary conditions in intensification because the features can effectively deepen the warm layer (depth of the $26^{\circ} \mathrm{C}$ isotherm reaching $100 \mathrm{~m}$ and upper-ocean heat content is $\sim 110 \mathrm{~kJ} \mathrm{~cm}^{-2}$ ) to restrain the typhoon's self-induced ocean cooling. In the past $13 \mathrm{yr}, 8$ out of the 30 category 5 typhoons (i.e., $27 \%$ ) belong to this situation.

The second type is the situation found in the gyre central region $\left(10^{\circ}-21^{\circ} \mathrm{N}, 121^{\circ}-170^{\circ} \mathrm{E}\right)$ where the background climatological warm layer is deep (typically the depth of the $26^{\circ} \mathrm{C}$ isotherm is $\sim 105-120 \mathrm{~m}$ and the upper-ocean heat content is $\sim 80-120 \mathrm{~kJ} \mathrm{~cm}^{-2}$ ). In this deep, warm background, passing over positive features is not critical since the background itself is already sufficient to restrain the self-induced cooling negative feedback during intensification.
\end{abstract}

\section{Introduction}

\section{a. Motivation}

Category $5^{1}[1-\mathrm{min}(10 \mathrm{~min})$ maximum sustained wind speed $>71(65) \mathrm{m} \mathrm{s}^{-1}$ ] tropical cyclones, Hurri-

\footnotetext{
${ }^{1}$ The Saffir-Simpson tropical cyclone scale based on the 1-min (10 min) maximum sustained winds: category 1: 34-43 (30-37) $\mathrm{m} \mathrm{s}^{-1}$, category 2: 44-50 (38-43) $\mathrm{m} \mathrm{s}^{-1}$, category 3 : 51-59 (44-51) $\mathrm{m} \mathrm{s}^{-1}$, category 4: 59-71 (52-61) $\mathrm{m} \mathrm{s}^{-1}$, and category 5: >71 (>61) $\mathrm{m} \mathrm{s}^{-1}$.

Corresponding author address: Dr. I.-I. Lin, Dept. of Atmospheric Sciences, National Taiwan University, No. 1, Sec. 4, Roosevelt Rd., Taipei 106, Taiwan.

E-mail: iilin@as.ntu.edu.tw
}

cane Katrina (2005) and Supertyphoon Maemi (2003) for instance, are the most intense and destructive cyclones on earth. Given their huge impact, it is important to understand why these storms can reach such extraordinary intensity. However, much remains unclear as a cyclone's intensification is a highly complex process involving the interaction of the atmosphere, ocean, and the cyclone's own structure (Gray 1979; Holliday and Thompson 1979; Emanuel 1986, 2000, 2006; Shay et al. 2000; Kaplan and DeMaria 2003; Wang and Wu 2003; Emanuel et al. 2004; Lin et al. 2005; Houze et al. 2007; Pun et al. 2007; Wu et al. 2007). In exploring the ocean's role in cyclone's intensification, it is necessary to consider not only sea surface temperature (SST), but the thermal structure of the upper-ocean column because cyclones interact not only just with the surface, but with 
the upper-ocean layer (typically from surface down to 100-200 m; Gray 1979; Holliday and Thompson 1979; Emanuel 1986; Shay et al. 2000; Goni and Trinanes 2003; Lin et al. 2003a,b; Emanuel et al. 2004; Lin et al. 2005; Scharroo et al. 2005; Pun et al. 2007; Wu et al. 2007). This is especially true for category 5 cyclones since the more intense the wind is, the deeper the ocean mixing is involved (Price 1981; Bender and Ginis 2000; Pun et al. 2007).

However, it has been difficult to explore the upperocean thermal structure (UOTS)-related issues because of the lack of subsurface observations, over the vast oceans (Gray 1979; Holliday and Thompson 1979; Emanuel 1986; Shay et al. 2000; Goni and Trinanes 2003; Emanuel et al. 2004; Lin et al. 2005; Scharroo et al. 2005). With the advancement in remote sensing (e.g., satellite altimetry; Fu et al. 1994) and in situ ocean measurements (e.g., Argo floats; Gould et al. 2004), it is now possible to study this subject with more reliable new observations. To conduct a systematic study, it is needed to have as many category 5 cyclone cases stretching for as longer period as possible. In this work, the western North Pacific Ocean ${ }^{2}$ is chosen for investigation because it is among the world's oceans where most category 5 cyclones (i.e., typhoons) are found (Holliday and Thompson 1979; Emanuel 1986). This work is presented in a series of two papers. In Part I (this paper), the role that ocean features play in category 5 typhoon's intensification is studied. In Part II, issues on translation speed related to UOTS will be explored.

\section{b. Issues on the interaction between ocean features and category 5 tropical cyclones}

Because of the presence of mesoscale ocean eddies, along with the change in the location of the currents, and the large-scale variability (e.g., El Niño), there exist many dynamic ocean features in certain high-impact tropical cyclone basins, such as the Gulf of Mexico and the western North Pacific Ocean (Wyrtki 1979; Philander 1990; Qiu 1999; Johnson et al. 2000; Shay et al. 2000; Roemmich and Gilson 2001; Goni and Trinanes 2003; Hwang et al. 2004; Emanuel et al. 2004; Lin et al. 2005; Scharroo et al. 2005; Oey et al. 2006). Since these dynamic features are perturbations from the climatology, they are generally not observable from the ocean climatological data (Stephens et al. 2002). With the advance in the remote sensing, these features nowadays

\footnotetext{
${ }^{2}$ From the best-track data of the JTWC during 1960-2005, in average 2.5 typhoons reached the category 5 intensity in the western North Pacific Ocean each year.
}

can be effectively detected by satellite altimeters ( $\mathrm{Fu}$ et al., 1994) as regions of positive or negative sea surface height anomalies (SSHAs; Goni et al. 1996; Qiu 1999; Shay et al. 2000; Goni and Trinanes 2003; Emanuel et al. 2004; Hwang et al. 2004; Lin et al. 2005; Pun et al. 2007). Positive-SSHA features (also referred to as warm features) are regions where the warm upperocean layer (warm ocean layer is often defined as from surface down to the depth of the $26^{\circ} \mathrm{C}$ isotherm, i.e., D26; Leipper and Volgenau 1972; Shay et al. 2000) is deeper than climatology (i.e., regions with increase warm layer thickness from the climatological thickness). On the other hand, negative-SSHA features are regions where warm upper-ocean layer shoals from climatology and are regions where warm layer thickness decreases (Qiu 1999; Shay et al. 2000; Goni and Trinanes 2003; Hwang et al. 2004; Lin et al. 2005; Scharroo et al. 2005; Pun et al. 2007). Besides D26, tropical cyclone heat potential or upper-ocean heat content (UOHC, i.e., the integrated heat content excess per unit area relative to D26 integrated from D26 to the surface) is another parameter that is often used in characterizing these features whereby in the positive (negative) features, the UOHC is higher (lower) than the climatological value (Leipper and Volgenau 1972; Shay et al. 2000; Goni and Trinanes 2003; Pun et al. 2007; Wada and Usui 2007). Also, it should be noted that these features are usually not differentiable by their SSTs but by the subsurface-related parameters (i.e., D26 or UOHC) since these features represent subsurface variabilities (Goni et al. 1996; Shay et al. 2000; Goni and Trinanes 2003; Lin et al. 2005; Pun et al. 2007).

Recent observations find that a notable number of category 5 cyclones, such as Hurricane Katrina (2005) (Scharroo et al. 2005), Rita (2005), Mitch (1998) (Emanuel et al. 2004), Supertyphoon Maemi (2003) (Lin et al. 2005), and Dianmu (2004) (Pun et al. 2007) intensified rapidly (Kaplan and DeMaria 2003) into the fifth category while they were moving over the positiveSSHA features. From this regard, the interaction between ocean features and category 5 cyclones is worth examining. Note that most existing works (Shay et al. 2000; Goni and Trinanes 2003; Emanuel et al. 2004; Lin et al. 2005; Scharroo et al. 2005; Pun et al. 2007) on this issue are based on case study of individual events. It is not clear whether more generalized conclusions can be deduced about the relation between the category $5 \mathrm{cy}$ clones and their passage over the positive-SSHA features. In this study, all category 5 typhoons (in total 30 cases) that occurred during the May-October typhoon season from 1993 to 2005 (i.e., 13 yr) are studied, since the main satellite instrument for observation, the 

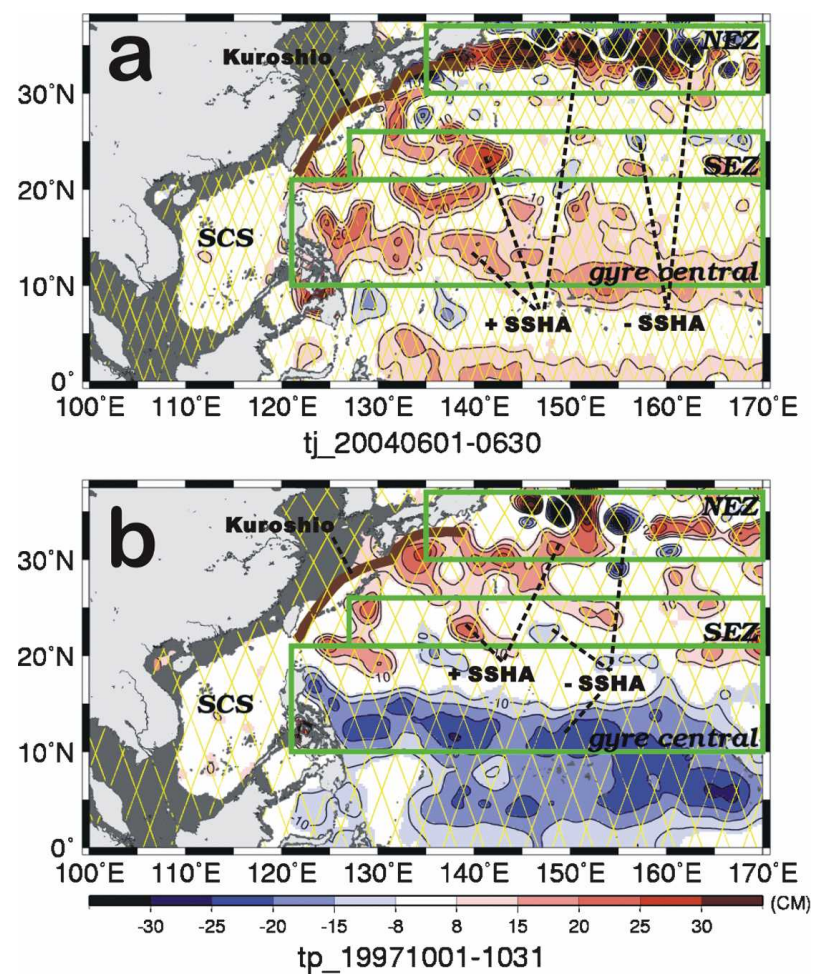

FIG. 1. Exemplary monthly averaged SSHA (cm) maps (a) June 2004 and (b) October 1997 from the TOPEX/Poseidon and $J a$ son-1 satellite altimeters (tracks depicted in yellow) showing that abundant positive (shaded in red) and negative (shaded in blue) SSHA features are present in the western North Pacific Ocean. The locations of the NEZ, SEZ, Kuroshio, gyre central, and the South China Sea (SCS) are depicted. Mesoscale features are often found in the NEZ and the SEZ; while large, basin-scale features are often found in the gyre central.

Ocean Topography Experiment (TOPEX)/Poseidon altimeter (Fu et al. 1994) became available starting from 1993. In section 2, the hydrographical setting in the western North Pacific, including the origin of the features and background climatology, is introduced. The data and methodology are presented in section 3. Results, discussions, and conclusions are given in sections 4-6.

\section{Hydrographic setting in the western North Pacific}

\section{a. Origin of the features}

Over the western North Pacific, abundant positiveand negative-SSHA features are present year-round, as clearly observed from the satellite altimetry SSHA maps (Fig. 1; Qiu 1999; Hwang et al. 2004; Lin et al. $2005)$. In the northern part $\left(30^{\circ}-37^{\circ} \mathrm{N}, 135^{\circ}-170^{\circ} \mathrm{E}\right)$, the features are often mesoscale features associated with the Kuroshio rings (Yasuda et al. 1992). These features are originated from the western boundary currents (Richard 1981; Pickard and Emery 1990; Yasuda et al.
1992) and are similar to the Gulf Stream rings (Shay et al. 2000). In the central part $\left(21^{\circ}-26^{\circ} \mathrm{N}, 127^{\circ}-170^{\circ} \mathrm{E}\right)$, features are associated with mesoscale eddies originated from the baroclinic instability of the weak flow between the westward North Equatorial Current and the eastward Subtropical Countercurrent (Qiu 1999; Roemmich and Gilson 2001). These two eddy-rich regions are commonly known as the north and the south eddy zone (NEZ and SEZ; Fig. 1; Qiu 1999; Roemmich and Gilson 2001; Hwang et al. 2004; Lin et al. 2005). To the west of the SEZ is the Kuroshio $\left(21^{\circ}-30^{\circ} \mathrm{N}, 121^{\circ}-\right.$ $127^{\circ} \mathrm{E}$ ) warm current region where features are caused by Kuroshio's variability (Qiu 1999). Moving southward to the region near $10^{\circ}-21^{\circ} \mathrm{N}, 121^{\circ}-170^{\circ} \mathrm{E}$ is the center part of the western subtropical gyre (referred to as the gyre central region in this study), where large, basin-scale features are found. These features are usually affected by large-scale processes, such as the El Niño (Wyrtki 1979; Philander 1990; Johnson et al. 2000). For example, during the El Niño period in October 1997, a large negative-SSHA feature $(<-20 \mathrm{~cm})$ is observed in the gyre central (Fig. 1b), while in June, 2004, a positive-SSHA feature is found (Fig. 1a).

\section{b. Background climatology}

With these features, the background climatological UOTS in the western North Pacific is constantly modulated. The background summer UOTS, in SST and the depth of the $26^{\circ} \mathrm{C}$ isotherm (D26), is illustrated for reference in Figs. 2a,b, respectively. As shown in the JulySeptember-averaged SST map from the Tropical Rainfall Measuring Mission (TRMM; Wentz et al., 2000) satellite during 2000-05 (Fig. 2a), due to the strong solar radiation in summer, uniformly warm SST of $\geqq 28^{\circ} \mathrm{C}$ covers most part of the western North Pacific Ocean (Fig. 2a). As for the corresponded D26 (data from the World Ocean Atlas 2001, Stephens et al. 2002; Fig. 2b), the mean thickest water lies in the gyre central region $\left(10^{\circ}-21^{\circ} \mathrm{N}, 121^{\circ}-170^{\circ} \mathrm{E}\right)$ with $\mathrm{D} 26$ in the range of $80-130 \mathrm{~m}$. In contrast, the thickness in the South China Sea $\left(5^{\circ}-20^{\circ} \mathrm{N}, 105^{\circ}-120^{\circ} \mathrm{E}\right)$ of the similar latitude is only about $20-70 \mathrm{~m}$. In the northern part of the gyre, that is, in the SEZ $\left(21^{\circ}-26^{\circ} \mathrm{N}, 127^{\circ}-170^{\circ} \mathrm{E}\right)$, it is found that the climatological D26 shoals significantly northward from 70 to $40 \mathrm{~m}$. In the Kuroshio warm current region $\left(21^{\circ}-30^{\circ} \mathrm{N}, 121^{\circ}-127^{\circ} \mathrm{E}\right)$, the mean D26 is between 50 and $80 \mathrm{~m}$. Farther north, the background D26 reduces to below $20 \mathrm{~m}$ at $30^{\circ} \mathrm{N}$ in the NEZ region.

\section{Data and methodology}

In this work, the best-track data from the Joint Typhoon Warning Center (JTWC) are used. The SST data 

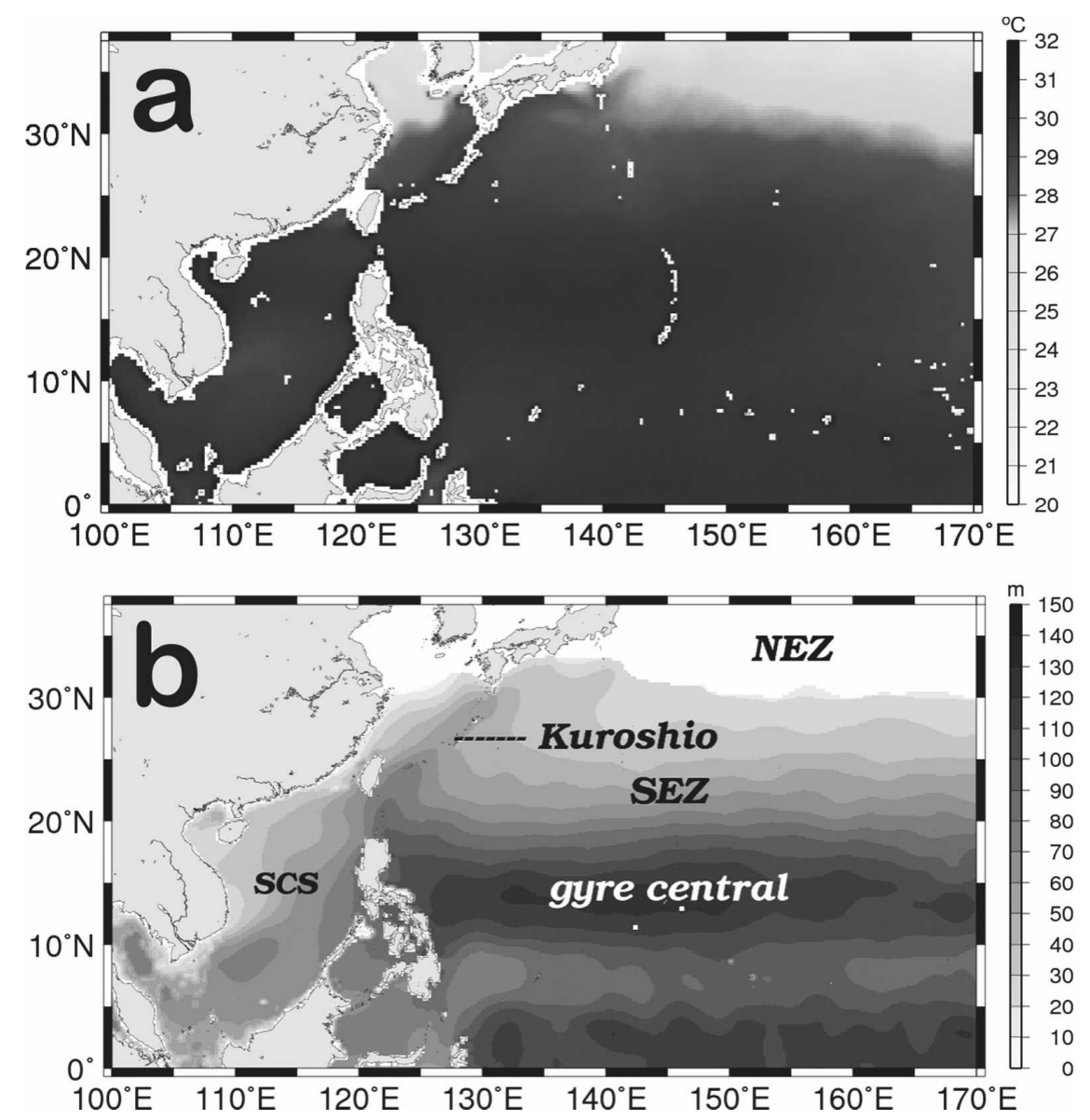

FIG. 2. The background climatological upper-ocean thermal structure (SST and D26) during the western North Pacific summer (July-September). (a) SST, as observed by the TRMM satellite during $2000-05$. (b) D26, data from the $0.25^{\circ}$ resolution monthly climatological data of the WOA01 (Stephens et al. 2002).

used is from the TRMM satellite (Wentz et al. 2000). Two satellite altimeters, that is, the TOPEX/Poseidon (starting from 1993) and Jason-1 (from 2002), are utilized to detect ocean features (Fu et al. 1994). The altimetry data used is the Geophysical Data Record (GDR) product from the National Aeronautics and Space Administration (NASA) Jet Propulsion Laboratory (JPL). The accuracy in sea surface height measurement is $3.3 \mathrm{~cm}$ and the nominal along-track spatial resolution is $7 \mathrm{~km}$ (see online at http://podaac.jpl.nasa.gov/ jason/documents/). For the 1993-2001 cases, TOPEX/ Poseidon altimetry data is used. As for the 2002-05 cases, Jason-1 data is added so as to maximize data usage. The corresponding maximum swath gap for single altimeter usage is $300 \mathrm{~km}$ and $150 \mathrm{~km}$ if two altimeters are used. For each typhoon case, the pretyphoon SSHA map from a 10-day altimetry cycle (gridded to $1 / 4^{\circ}$ from the along-track data) is used to identify the primary ocean feature (i.e., the feature type that the typhoons encounter for the longest time during intensification). Here the intensification period is defined as from category 1 to the peak category 5 intensity. Three categories of primary features are defined as follows: positive-SSHA feature (averaged SSHA $>6 \mathrm{~cm}$ ), negative-SSHA feature (averaged SSHA $<-6 \mathrm{~cm}$ ), and no-feature condition (averaged SSHA between -6 and 6 cm; Fu et al. 1994; Qiu 1999; Shay et al. 2000; Goni and Trinanes 2003; Hwang et al. 2004; Lin et al. 2005; Pun et al. 2007).

To assess the detailed upper-ocean thermal structure, the available in situ near coincident/collocated upperocean thermal structure profiles from the Argo float (Gould et al. 2004) and the National Oceanic and Atmospheric Administration/Global Temperature and Salinity Profile Program (NOAA/GTSPP) database (Keeley et al. 2003) are cross-examined for each case. All profiles are acquired within 1 week prior to the passage of the typhoon. Among the 30 cases, in situ 
profiles were identified in 11 cases. Most of the profiles are located on the track or within $0.5^{\circ}$ from the storm center while profiles for three cases are around $1.5^{\circ}-2^{\circ}$ from the track. By comparing the in situ profiles with the climatological profiles [from the World Ocean Atlas 2001 (WOA01; Stephens et al. 2002) along the storm tracks, the deepening and shoaling of D26 caused by the features can be assessed. Also UOHC (i.e., $\left.Q_{H}\right)^{3}$ is calculated for each in situ and climatological profile so as to assess the increase (or decrease) in UOHC due to the presence of features.

To estimate the ocean's negative feedback to intensity from a typhoon's self-induced ocean cooling (Price 1981; Emanuel 1999; Bender and Ginis 2000; Cione and Uhlhorn 2003), the Price-Weller-Pinkel ocean mixed layer model (Price et al. 1986; Jacob et al. 2000; Jacob and Shay 2003; Lin et al. 2003b) is used. The searched pretyphoon in situ profiles in the features are adopted as initial profiles. Another reference set of initial profiles used are the background climatological profiles (Stephens et al. 2002), so as to estimate the self-cooling under climatological condition. For each profile, the storm-induced cooling is estimated progressively with increase in wind forcing from category 1 to 5, according to the Saffir-Simpson scale. The 10-min average maximum sustained wind, ranging from 30 to $65 \mathrm{~m} \mathrm{~s}^{-1}$, for every $5 \mathrm{~m} \mathrm{~s}^{-1}$ interval, is used to drive the model. The drag coefficient $\left(C_{d}\right)$ from Powell et al. (2003) is used as the coefficient under the cyclone-wind condition.

Experiments are run under various translation speeds $\left(U_{h}\right)$, because the typhoon-induced SST cooling is not only a function of wind speed, but also a function of the translation speed $\left(U_{h}\right)$; that is, the faster the storm moves, the less the SST cooling is induced (Price 1981). As shown in Fig. 3, in the simulation, a parameter, $\mathrm{TC}_{\text {transit-time, }}$, is calculated as

$$
\mathrm{TC}_{\text {transi-time }}=D / U_{h},
$$

where $D$ represents the inner-core diameter. Thus, $\mathrm{TC}_{\text {transit-time }}$ is the time needed for the inner core of the typhoon to pass over a specific point location in the ocean (Cione and Uhlhorn 2003). Therefore, for each point location, the mixed layer model is run according to the $\mathrm{TC}_{\text {transit-time. }}$ The inner-core diameter $D$ is de-

\footnotetext{
${ }^{3}$ Note: $Q_{H}=c_{p} \rho \sum_{i=1}^{n} \Delta T\left(x, y, z_{i}, t\right) \Delta Z$, where $c_{p}$ is the capacity heat of the seawater at constant pressure taken as $4178 \mathrm{~J} \mathrm{~kg}^{-1}$ ${ }^{\circ} \mathrm{C}^{-1}, \rho$ is the average seawater density of the upper ocean taken as $1026 \mathrm{~kg} \mathrm{~m}^{-3}$, and $\Delta T\left(x, y, z_{i}, t\right)$ is the temperature difference between $T\left(z_{i}\right)$ and $26^{\circ} \mathrm{C}$ at depth $z_{i}$, and $\Delta Z$ is the depth increment taken at $5 \mathrm{~m}$. Here $n$ is the total layers from surface to the depth of $26^{\circ} \mathrm{C}$ (D26). The total UOHC is the sum of UOHC at each depth increment $(\Delta Z)$ through the surface to the D26.
}
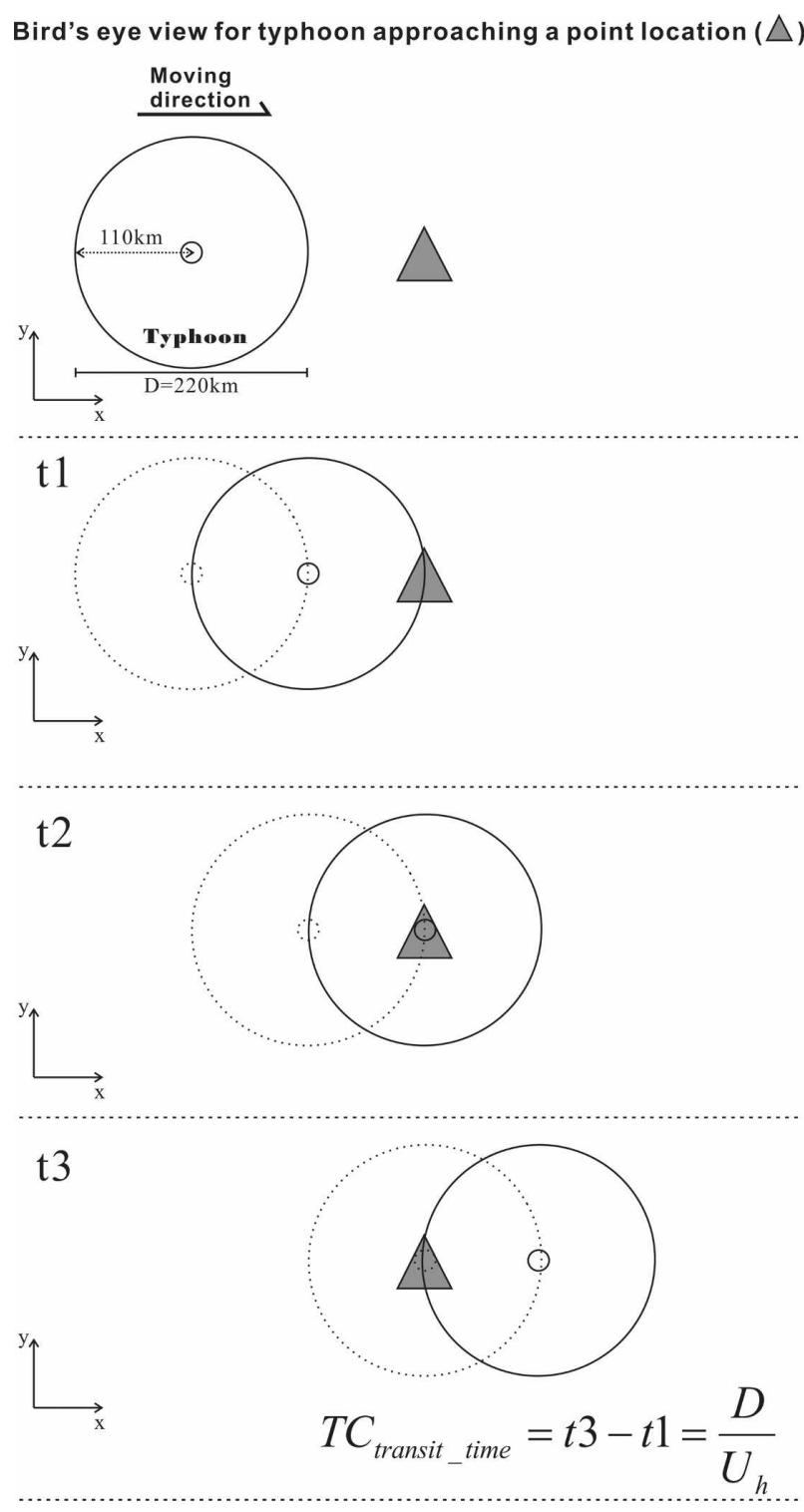

FIG. 3. Schematic diagram showing the situation as the typhoon approaches a point location in the ocean, as simulated by the 1D mixed layer model. The inner core diameter $(D)$ used in this work is $220 \mathrm{~km}$ and the TC transit time is calculated as $D / U_{h}$.

fined as $220 \mathrm{~km}$ in this work because the western North Pacific typhoons are generally $\sim 1.2-1.4$ times the size of the Atlantic hurricanes (Merrill 1984; Liu and Chan 1999) and the reported mean inner-core diameter for the Atlantic hurricanes is $180 \mathrm{~km}$ (Cione and Uhlhorn 2003).

In this work, the threshold criterion from Emanuel (1999) is adopted, that is, the self-induced SST cooling exceeding $2.5^{\circ} \mathrm{C}$ is regarded as an unsuitable condition for intensification, because such cooling would be sufficient to shut down the entire energy production of a storm (Gallacher et al. 1989; Emanuel 1999; Emanuel 


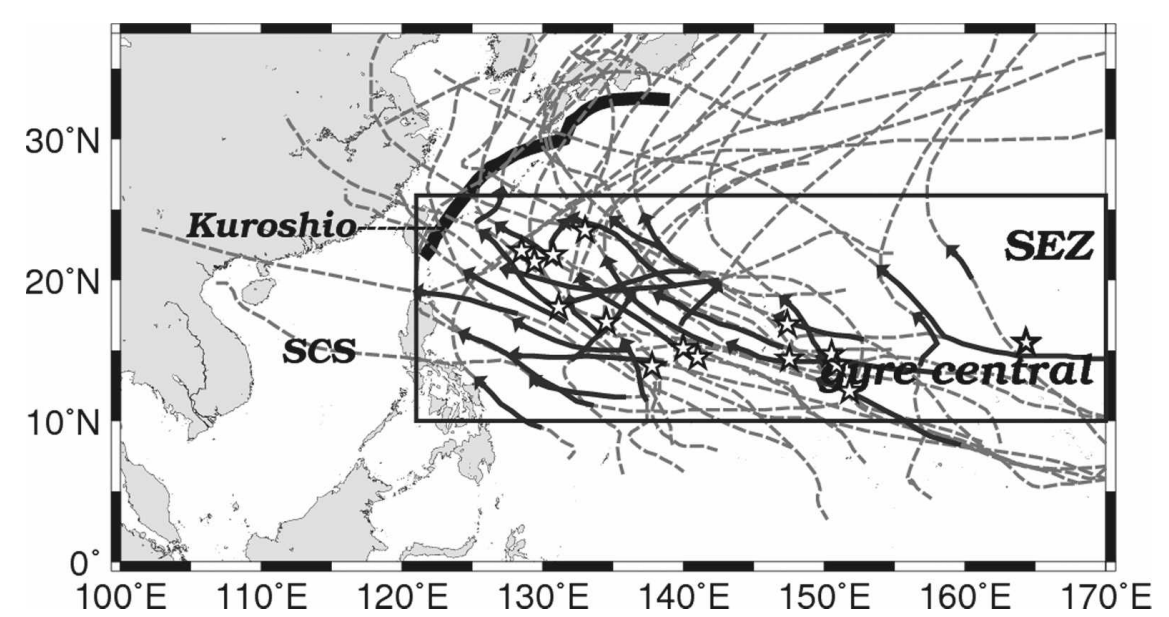

FIG. 4. Full tracks (dashed gray) and the intensification (from categories 1 to 5) track segment (solid black with arrows) of the 30 category 5 typhoons occurred during MayOctober between 1993 and 2005. Locations of the in situ profiles are depicted as stars.

et al. 2004). To further substantiate this, air-sea sensible and latent heat flux is estimated and is discussed in section 5b. Finally, since Price et al. (1986) is a simple 1D mixed layer model, in the discussion section (section 5c), a 3D numerical experiment is run using U.S. Naval Research Laboratory (NRL) Ocean/Nowcast Forecast System for the East Asian Seas (EASNFS) ocean model (Ko et al. 2003; Chapman et al. 2004) to discuss the possible difference between $1 \mathrm{D}$ and 3D simulations related to this work (Jacob et al. 2000; Jacob and Shay 2003).

\section{Results}

Figure 4 depicts the full track (in dashed gray) and the intensification track segments (in solid black with arrows, i.e., during the intensification period from category 1 to the peak category 5 intensity) for the 30 cases. Even though the full tracks of typhoons cover the entire western North Pacific region, it can be found that the intensification process only occurs while the storms are located in the SEZ $\left(21^{\circ}-26^{\circ} \mathrm{N}, 127^{\circ}-170^{\circ} \mathrm{E}\right)$, the gyre central $\left(10^{\circ}-21^{\circ} \mathrm{N}, 121^{\circ}-170^{\circ} \mathrm{E}\right)$, and the southern part of the Kuroshio region $\left(21^{\circ}-26^{\circ} \mathrm{N}, 121^{\circ}-127^{\circ} \mathrm{E}\right)$. Among the 30 cases, 7 storms peak in the SEZ (Table 1), 22 peak in the gyre central (Table 3 ), and 1 peaks in the Kuroshio region (Table 5). The results are presented as follows.

\section{a. The south eddy zone cases: Positive SSHA features}

Figure 5 depicts the SSHA features the typhoons encounter during intensification for the seven cases at the SEZ. It is found that the SSHA features in all these seven cases are positive cases. As shown in Figs. 5b,f, some typhoons are observed to intensify all the way from category 1 to 5 when passing over these positiveSSHA features. The intensification of the other cases (e.g., Figs. 5a,c,d,e,g) is similar to the processes associated with those well-known category 5 cases in the Atlantic/Gulf of Mexico. For example, Mitch (1998) and Katrina (2005), which both passed over positive-SSHA features for a considerable period of time (typically intensified for more than two categories) during their intensification (Emanuel et al. 2004; Lin et al. 2005; Scharroo et al. 2005).

TABLE 1. The seven SEZ cases and the primary features encountered during intensification. The intensification period and the average translation speed $\left(U_{h}\right)$ when passing over features are also summarized.

\begin{tabular}{lcccc}
\hline \hline Typhoon & Month and year & Intensification period & Primary feature & Altimetry cycle $^{U_{h}\left(\mathrm{~m} \mathrm{~s}^{-1}\right)}$ \\
\hline a. 95_17 & Sep 1995 & 0000 UTC 14-0600 UTC 15 Sep & + & 3 Sep-12 Sep \\
b. Eve & Jul 1996 & 0000 UTC 15-0000 UTC 16 Jul & + & 4 Jul-13 Jul \\
c. Herb & Jul 1996 & 0000 UTC 26-1800 UTC 30 Jul & + & 5.2 \\
d. Ginger & Sep 1997 & 0000 UTC 26-0000 UTC 27 Sep & + & 4.5 -25 Jul \\
e. Saomai & Sep 2000 & 1200 UTC 8-1200 UTC 10 Sep & + & 16 Sep-25 Sep \\
f. Maemi & Sep 2003 & 1800 UTC 8-0000 UTC 10 Sep & + & 3.7 Aug-6 Sep \\
g. Maon & Oct 2004 & 0000 UTC 7-0000 UTC 8 Oct & + & 28 Aug-6 Sep \\
\hline
\end{tabular}



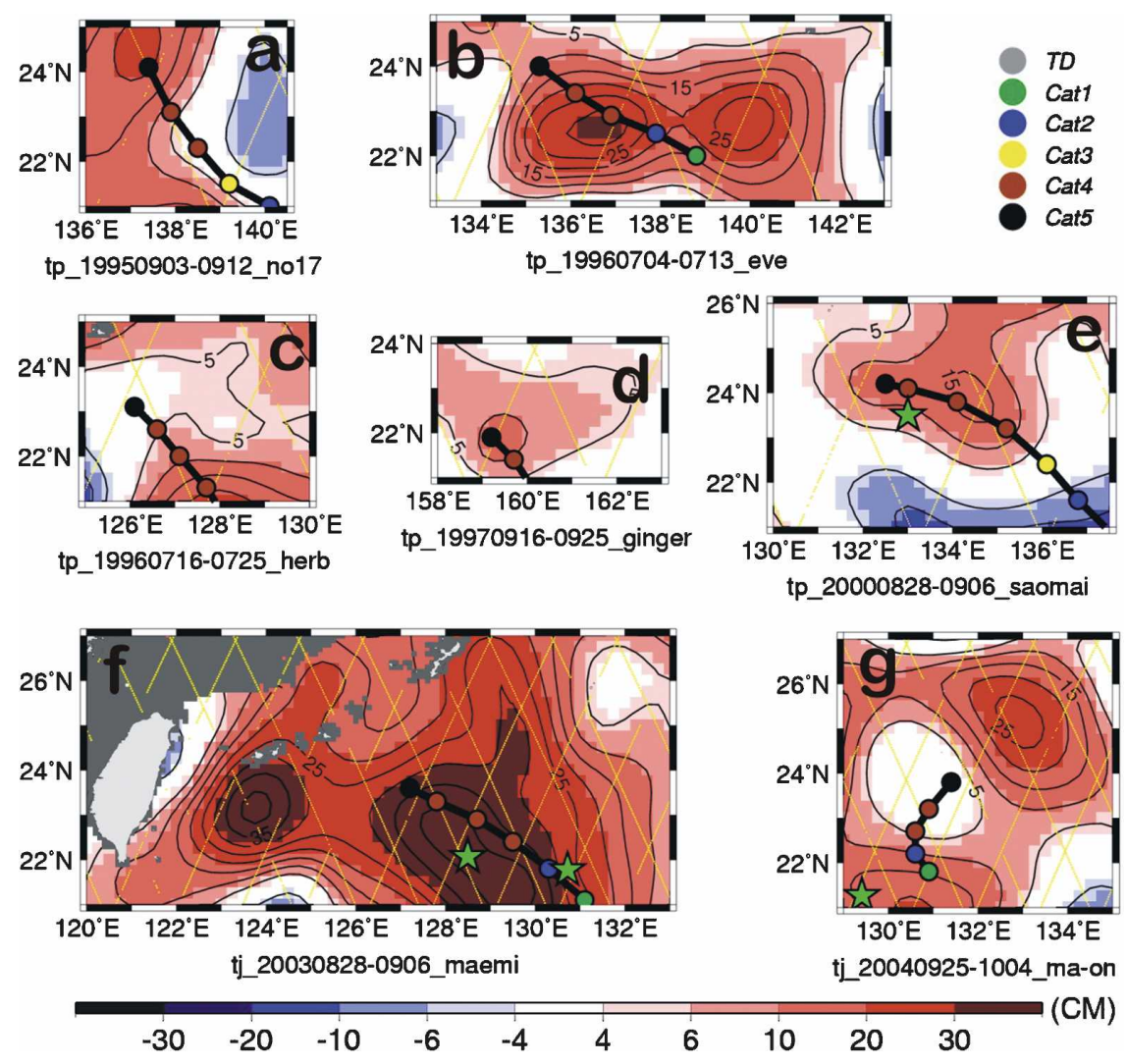

FIG. 5. Pretyphoon SSHA (cm) maps and the tracks of the seven SEZ cases (in chronological order, see also Table 1). Locations of the in situ profiles are depicted as green stars. The altimetry tracks are depicted in yellow.

Based on the in situ profiles (solid black profiles in Fig. 6) in these features (locations depicted in Figs. $5 \mathrm{~b}, \mathrm{f}, \mathrm{g})$, it is shown that the region with positive-SSHA features contains the warm water extending much deeper than that under the climatological condition (dashed gray profiles in Fig. 6). As summarized in Table 2, both D26 and UOHC increase significantly. In the positive feature regions, D26 reaches as deep as $90-120 \mathrm{~m}$ whereas the climatological D26 is only around of 40-65 m while UOHC also increases significantly from an average of 47 to $109 \mathrm{~kJ} \mathrm{~cm}^{-2}$ (i.e., $>100 \%$ increase; Table 2).

With this large increase in the warm layer thickness and UOHC, the corresponding impact in storminduced SST cooling is assessed. The storm-induced SST cooling estimation averaged over all climatological profiles (dashed gray profiles in Fig. 6) under 10 different translation speeds (i.e., $U_{h}=1,2,3, \ldots, 10 \mathrm{~m} \mathrm{~s}^{-1}$ ) are depicted in Fig. 7a. The estimations based on the in situ profiles in the positive-SSHA features (solid black profiles in Fig. 6) are depicted in Fig. 7b. In these figures, regions of storm-induced SST cooling exceeding the $2.5^{\circ} \mathrm{C}$ threshold are shaded, indicating the unfavor- able condition for intensification (Emanuel 1999). The comparison of Figs. 7a,b shows that under the same translation speed and wind forcing ( $x$ axis), the storminduced SST cooling ( $y$ axis) is evidently larger under the climatological condition (Fig. 7a) than under the condition with the positive-SSHA features (Fig. 7b). As an example, for a typhoon moving at $U_{h}=5 \mathrm{~m} \mathrm{~s}^{-1}$ and with $60 \mathrm{~m} \mathrm{~s}^{-1}$ wind speed, the averaged storm-induced cooling is $2.6^{\circ} \mathrm{C}$ under the climatological condition (black curve with squares in Fig. 7a). However, under the positive-SSHA situation, the corresponding SST cooling is only around $1.0^{\circ} \mathrm{C}$ (black curve with squares in Fig. 7b). This clearly shows that the storm-induced SST cooling are limited in the area with the positiveSSHA features (Cione and Uhlhorn 2003; Lin et al. 2005).

During the intensification period for these 7 cases over the SEZ (Table 1), the observed storm translation speeds are in the range between 3.0 and $5.3 \mathrm{~m} \mathrm{~s}^{-1}$. Given this range of translation speeds in Fig. $7 \mathrm{a}$, the corresponding storm-induced SST cooling starts to fall into the shaded region for category 3 (i.e., the black curve with triangles for $U_{h}=3 \mathrm{~m} \mathrm{~s}^{-1}$ in Fig. 7a) or 


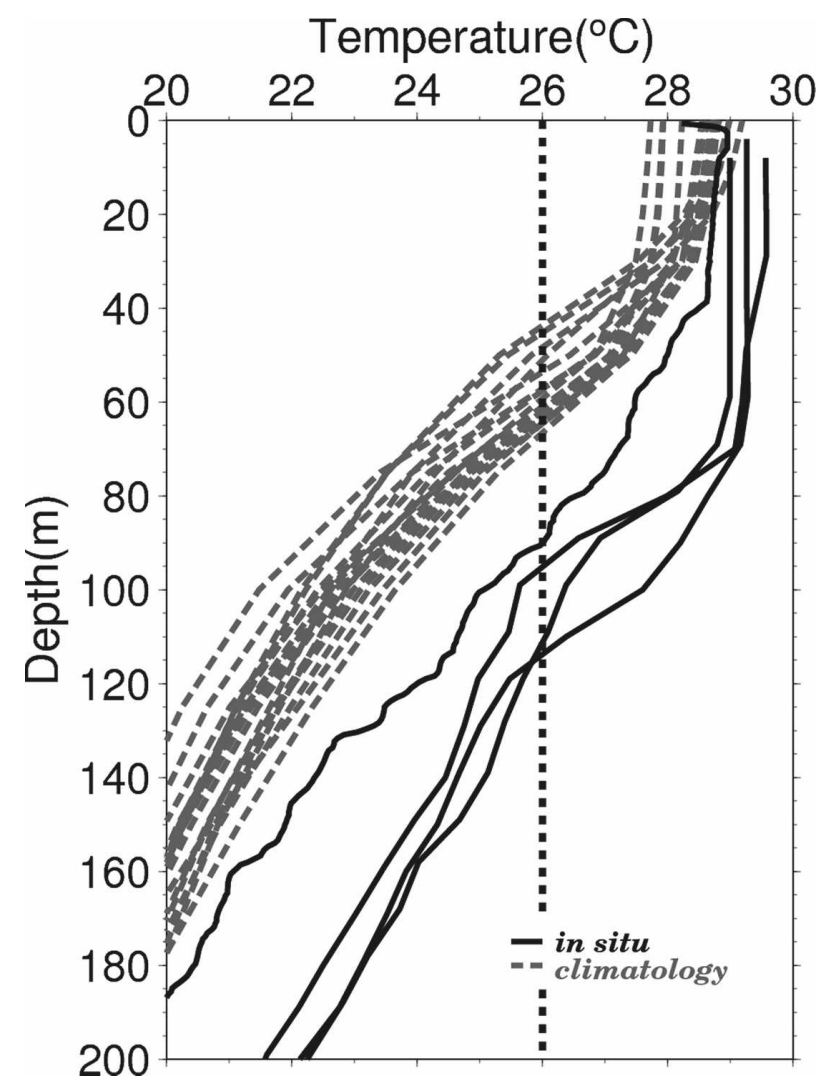

FIG. 6. In situ depth-temperature profiles found in the positiveSSHA features in the SEZ (location depicted as green stars in Fig. 5). For comparison, the background climatological profiles along the track of the seven SEZ cases are also depicted (dashed gray profiles).

category 4 typhoons (i.e., the black curve with diamonds and black curve with squares for $U_{h}=4$ and 5 $\mathrm{m} \mathrm{s}^{-1}$ in Fig. 7a). As in Fig. 7a, one sees that at category 4 , the self-induced cooling can already reach as much as $3.5^{\circ} \mathrm{C}$, indicating unfavorable condition for continual intensification (i.e., no more energy supply; Gallacher et al. 1989; Emanuel 1999) to the fifth category under the climatological condition in the SEZ. As the ocean is a necessary condition in intensification (Holliday and Thompson 1979; Emanuel 1986), this shows that it is not possible to support intensification to category 5 under the climatological upper-ocean thermal structure in the SEZ, even if other conditions (e.g., atmosphere) are favorable.

However, under the positive-SSHA feature situation, the corresponding storm-induced SST cooling at this observed range of translation speeds is much smaller. As seen in Fig. 7b, given $U_{h}=3,4$, and $5 \mathrm{~m} \mathrm{~s}^{-1}$, storminduced SST cooling never falls into the shaded region throughout the intensification period from category 1 to 5 . Even with the intense $65 \mathrm{~m} \mathrm{~s}^{-1}$ wind, the storminduced SST cooling is still only around $1.2^{\circ} \mathrm{C}$ when traveling at $U_{h}=5 \mathrm{~m} \mathrm{~s}^{-1}$ (black curve with squares in Fig. 7b). These results explain why all SEZ cases in the past $13 \mathrm{yr}$ all passed over positive features because the presence of the positive-SSHA features can effectively suppress the self-induced cooling. Otherwise, it will not be possible to satisfy the ocean's necessary condition under the climatological UOTS in the SEZ.

\section{b. Cases in the gyre central region}

Table 3 and Fig. 8 summarize the primary features in the gyre central region that the 22 cases of typhoons encountered while intensifying to the fifth category. It is found that the intensification of typhoons to category 5 not only exists when they are over the positive-SSHA features (e.g., Figs. 8b,s), but also on the normal (i.e., no primary features, e.g., Figs. 8f,t) and even negative SSHA features (e.g., Figs. 8i-k). As summarized in Table 3, among the 22 gyre cases, 17 typhoons belong to the positive-SSHA feature scenario, 2 belong to the normal scenario, and 3 belong to the negative-SSHA feature scenario. These three different scenarios are discussed.

\section{1) Negative-SSHA features Scenario}

As in Figs. 8i-k, three category 5 typhoons were observed to intensify to the fifth cateogory while passing the negative-SSHA features (SSHA $\sim-10$ to $-30 \mathrm{~cm}$ ). In the positive-SSHA scenario, the warm layer thickness is larger than the climatological thickness (Shay et al. 2000; Goni and Trinanes 2003; Emanuel et al. 2004; Lin et al. 2005; Pun et al. 2007), hence it is understandable that with increase in the warm layer thickness, intensification is even more favorable. However, the negative-SSHA scenario is the opposite, the warm layer

TABLE 2. Comparison of D26, UOHC, and SST between in situ profiles in the positive-SSHA features and the background climatology.

\begin{tabular}{|c|c|c|c|c|c|c|c|c|c|}
\hline In situ profiles & $\begin{array}{c}\text { In situ } \\
\text { D26 (m) }\end{array}$ & $\begin{array}{c}\text { D26 (m) } \\
\text { (climatology) }\end{array}$ & $\begin{array}{l}\Delta \mathrm{D} 26 \\
(\mathrm{~m})\end{array}$ & $\begin{array}{c}\text { In situ } \\
\mathrm{UOHC} \\
\left(\mathrm{kJ} \mathrm{cm}{ }^{-2}\right)\end{array}$ & $\begin{array}{c}\text { UOHC } \\
\text { (climatology) } \\
\left(\mathrm{kJ} \mathrm{cm}^{-2}\right)\end{array}$ & $\begin{array}{c}\Delta \mathrm{UOHC} \\
\left(\mathrm{kJ} \mathrm{cm}{ }^{-2}\right)\end{array}$ & $\begin{array}{c}\text { In situ } \\
\text { SST }\left({ }^{\circ} \mathrm{C}\right)\end{array}$ & $\begin{array}{l}\text { SST } \\
\left({ }^{\circ} \mathrm{C}\right)\end{array}$ & $\begin{array}{c}\Delta \mathrm{SST} \\
\left({ }^{\circ} \mathrm{C}\right) \\
\end{array}$ \\
\hline Saomai (2000) & 90 & 58 & +32 & 73 & 44 & +29 & 28.2 & 28.5 & -0.3 \\
\hline Maemi_1 & 114 & 63 & +51 & 133 & 52 & +81 & 29.3 & 28.7 & +0.6 \\
\hline Maemi_2 & 95 & 63 & +32 & 119 & 51 & +68 & 29.6 & 28.7 & +0.9 \\
\hline Maon & 111 & 63 & +48 & 109 & 40 & +69 & 29.0 & 27.9 & +1.1 \\
\hline Avg & 103 & 62 & +41 & 109 & 47 & +62 & 29 & 28.5 & +0.5 \\
\hline
\end{tabular}



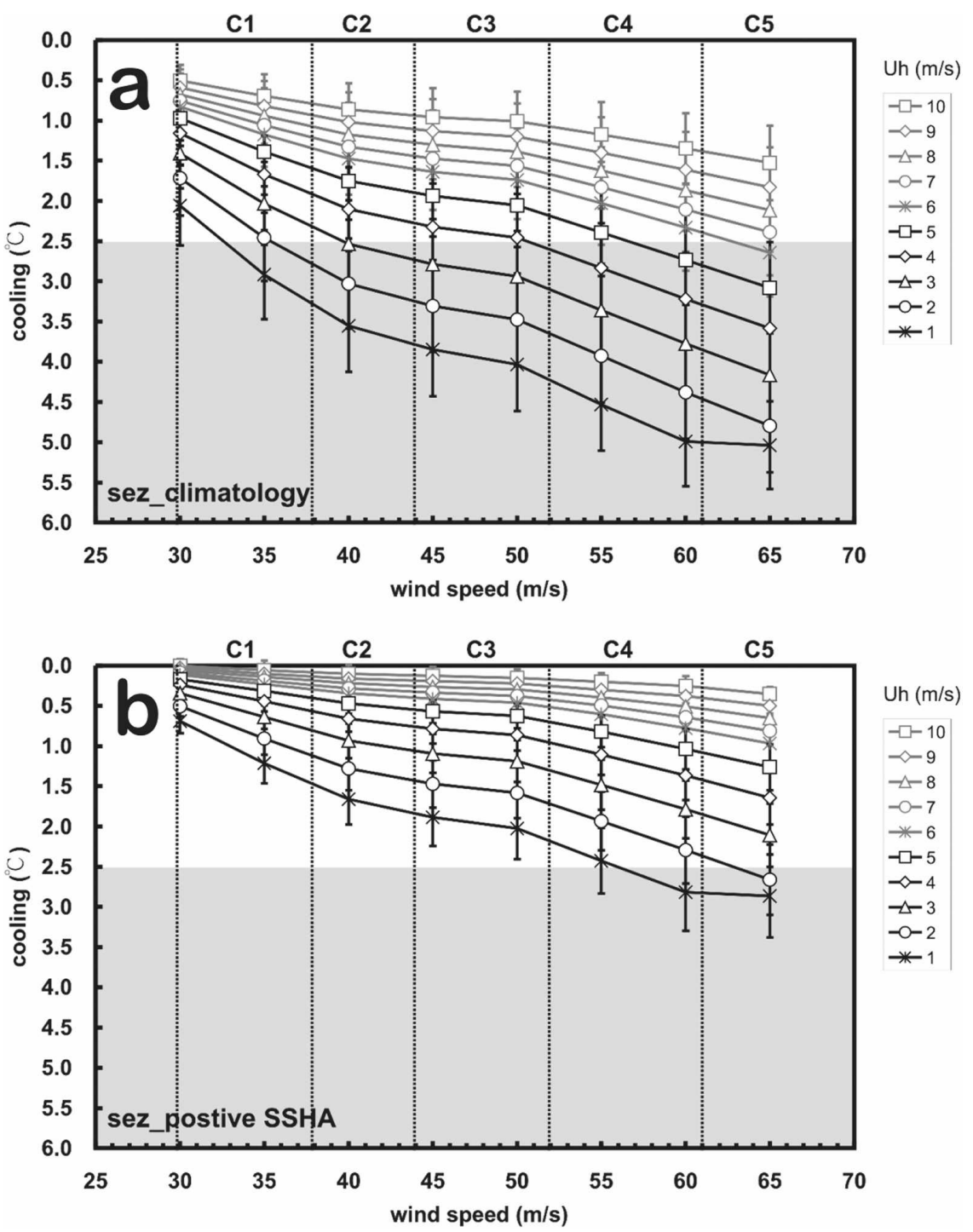

FIG. 7. Estimation of typhoon's self-induced ocean cooling using the Price-Weller-Pinkel ocean mixed layer model (Price et al. 1986) for the SEZ cases. The storm-induced cooling is estimated progressively with increase in wind forcing (every $5 \mathrm{~m} \mathrm{~s}^{-1}$ interval) from categories 1 to 5 (denoted as C1-C5) at various translation speeds $\left(U_{h}=1,2,3, \ldots, 10 \mathrm{~m} \mathrm{~s}^{-1}\right)$. The region of self-induced cooling exceeding the $2.5^{\circ} \mathrm{C}$ threshold (from Emanuel 1999) is shaded in gray, indicating an unsuitable condition for intensification. (a) Estimation based on the climatological profiles (dashed gray profiles in Fig. 6) along the typhoon tracks. (b) Estimation based on the in situ profiles (solid black profiles in Fig. 6) inside the positive-SSHA features.

shoals and the warm layer thickness is smaller than the climatological thickness. So one would wonder why under such shoaling situation the storm would still intensify to the fifth category.

Comparing the in situ profiles in the negative-SSHA features (solid black profiles in Fig. 9a, profile locations depicted in Fig. 8j and Table 4) with the climatological profiles in the gyre central region for these negativeSSHA cases (dashed gray profiles in Fig. 9a), one sees that the D26 shoals from the climatological value of 105 to $67-74 \mathrm{~m}$, that is, an average decrease of the warm layer thickness by $35 \mathrm{~m}$ (Table 4a) and UOHC from 103 to $80 \mathrm{~kJ} \mathrm{~cm}^{-2}$. It should be noted that the observed negative-SSHA features have the thermal structure with the shallower warm layer, but not the reduced SST. As in Fig. 9a and Table 4a, both climatological and in situ SST show the very warm SST of around $29^{\circ} \mathrm{C}$. In other words, the negative-SSHA features indicate a "shallower" warm layer situation, but not a "reduced SST" situation. 
TABLE 3. The 22 gyre cases and the primary features encountered during intensification. The intensification period and the average translation speed $\left(U_{h}\right)$ when passing over features are also summarized. Negative-SSHA cases: i, j, and k; observed range of $U h$ : 6.2$7.2 \mathrm{~m} \mathrm{~s}^{-1}$. Normal cases: $\mathrm{f}$ and $\mathrm{t}$; observed range of $U h: 3.0-6.4 \mathrm{~m} \mathrm{~s}^{-1}$. Positive-SSHA cases: a-e, g, h, l-s, u, and v; observed range of Uh: $2.3-9.4 \mathrm{~m} \mathrm{~s}^{-1}$.

\begin{tabular}{|c|c|c|c|c|c|}
\hline Typhoon & Month and year & Intensification period & Primary feature & Altimetry cycle & $U_{h}\left(\mathrm{~m} \mathrm{~s}^{-1}\right)$ \\
\hline a. $93 \_25$ & Oct 1993 & 0000 UTC 2-1200 UTC 4 Oct & + & $21 \mathrm{Sep}-30 \mathrm{Sep}$ & 4.8 \\
\hline b. $94 \_17$ & Aug 1994 & 0000 UTC 4-1800 UTC 5 Aug & + & 23 Jul-1 Aug & 5.3 \\
\hline c. $95 \_26$ & Oct 1995 & 0000 UTC $18-1200$ UTC 19 Oct & + & 6 Oct -15 Oct & 8.2 \\
\hline d. 95_29 & Oct 1995 & 0600 UTC 30-0000 UTC 1 Oct & + & 17 Oct-26 Oct & 4.3 \\
\hline e. Sally & Sep 1996 & 1200 UTC 6-1800 UTC 7 Sep & + & 24 Aug-4 Sep & 8.8 \\
\hline f. Nestor & Jun 1997 & 1800 UTC 8-1200 UTC 10 Jun & Normal & 28 May-6 Jun & 3.0 \\
\hline g. Rosie & Jul 1997 & 0600 UTC 21-1200 UTC 22 Jul & + & 10 Jul-19 Jul & 3.0 \\
\hline h. Winnie & Aug 1997 & 0600 UTC 10-0000 UTC 12 Aug & + & $30 \mathrm{Jul}-8$ Aug & 5.0 \\
\hline i. Ivan & Oct 1997 & 1800 UTC $15-1800$ UTC 17 Oct & - & 4 Oct-13 Oct & 7.2 \\
\hline j. Joan & Oct 1997 & 1800 UTC $15-0600$ UTC 17 Oct & - & 4 Oct-13 Oct & 6.7 \\
\hline k. Keith & Oct 1997 & 1200 UTC 30 Oct-1200 UTC 1 Nov & - & 10 Oct-28 Oct & 6.2 \\
\hline 1. Zeb & Oct 1998 & 1800 UTC $11-1200$ UTC 13 Oct & + & 30 Sep-9 Oct & 7.0 \\
\hline m. Damrey & May 2000 & 0600 UTC 8-1800 UTC 9 May & + & 25 Apr-5 May & 3.7 \\
\hline n. Bilis & Aug 2000 & 0600 UTC 20-1800 UTC 21 Aug & + & 8 Aug-17 Aug & 6.0 \\
\hline o. Podul & Oct 2001 & 0600 UTC 22-0600 UTC 24 Oct & + & 11 Oct-20 Oct & 2.3 \\
\hline p. Hagibis & May 2002 & 1200 UTC 18-1200 UTC 19 May & + & 6 May-15 May & 3.6 \\
\hline q.Fengshen & Jul 2002 & 0000 UTC 15-1200 UTC 21 Jul & + & 4 Jul-13 Jul & 2.7 \\
\hline r. Nida & May 2004 & 0000 UTC 15-1200 UTC 16 May & + & 4 May-13 May & 4.5 \\
\hline s. Dianmu & Jun 2004 & 0000 UTC 15-0600 UTC 16 Jun & + & 3 Jun-12 Jun & 3.6 \\
\hline t. Chaba & Aug 2004 & 1200 UTC 21-0000 UTC 23 Aug & Normal & 9 Aug-18 Aug & 6.4 \\
\hline u. Haitang & Jul 2005 & 0600 UTC 14-1200 UTC 16 Jul & + & 2 Jul-11 Jul & 9.4 \\
\hline v. Nabi & Aug 2005 & 1800 UTC 30 Jul-1800 UTC 1 Aug & + & 19 Aug-28 Aug & 5.0 \\
\hline
\end{tabular}

As for the corresponding storm-induced SST cooling, more pronounced cooling is expected when the storm is over the negative-SSHA feature (Fig. 10b) than under the climatological condition (Fig. 10a). Note that the storm-induced SST cooling falls to the shaded region only when $U_{h}=1-2 \mathrm{~m} \mathrm{~s}^{-1}$ under climatology (black curve with stars and black curve with circles in Fig. 10a). On the other hand, when over the negative-SSHA features, the cooling falls below the threshold at $U_{h}=$ $1-5 \mathrm{~m} \mathrm{~s}^{-1}$ (black curves in Fig. 10b). Though cooling is more pronounced in the negative-SSHA features, these negative-SSHA features are found in the gyre central region, that is, a shoaling situation from an existing thick, warm layer (D26 80-115 m, as in Fig. 2b, and dashed gray profiles in Fig. 9a). Therefore, even after shoaling from the negative-SSHA features, the warm layer thickness (in D26) is still around $67-74 \mathrm{~m}$ and UOHC is around $80 \mathrm{~kJ} \mathrm{~cm}^{-2}$ (solid black profiles in Fig. 9a; Table 4a). Figure 10b shows that if a storm is fast moving (i.e., $U_{h}=6-10 \mathrm{~m} \mathrm{~s}^{-1}$ ), the self-induced cooling will not exceed the threshold limit since the faster the storm travels, the less pronounced self-induced cooling is induced (Price 1981). Examining the observed translation speed (based on JTWC's best-track data) in Table 3, these three cases are indeed all relatively fasttraveling storms with $U_{h}$ between 6.2 and $7.2 \mathrm{~m} \mathrm{~s}^{-1}$.

In all, it is suggested that two conditions have to be met for storms to reach the category 5 intensity while they are over the negative-SSHA features. First, the negative-SSHA features are over an existing thick enough warm layer, such as over the gyre central region. Second, the storm has to move at a fast enough speed to reduce the negative impact from the self-induced SST cooling. In this work, three real cases of typhoon that reached category 5 while passing the negative SSHA features are demonstrated (cases i, j, k, in Table 3 and Fig. 8).

Interestingly, note that all three cases (Ivan, Joan, and Keith, cases i, j, k in Table 3 and Fig. 8) occurred during the El Niño period in October 1997. This suggest that the observed negative-SSHA features are part of the large-scale shoaling in the western North Pacific gyre (also see Fig. 1b) because the warm water piled to the eastern Pacific Ocean during El Niño (Wyrtki 1979; Philander 1990; Johnson et al. 2000).

\section{2) Normal (no feature) SCENARio}

As for the cases that do not pass over specific primary features (e.g., Figs. 8f,t), it is understandable that under this no-feature situation, with no deepening or shoaling, the in situ profiles (solid black profiles) are very similar to the climatological profiles (dashed gray profiles) in Fig. 9b (see also Table 4b). Under this circumstance, the estimated storm-induced SST cooling under both in situ (Fig. 10c) and climatological (Fig. 10a) conditions is also similar. From Table $4 \mathrm{~b}$, one sees that since the climatological warm layer is already as 

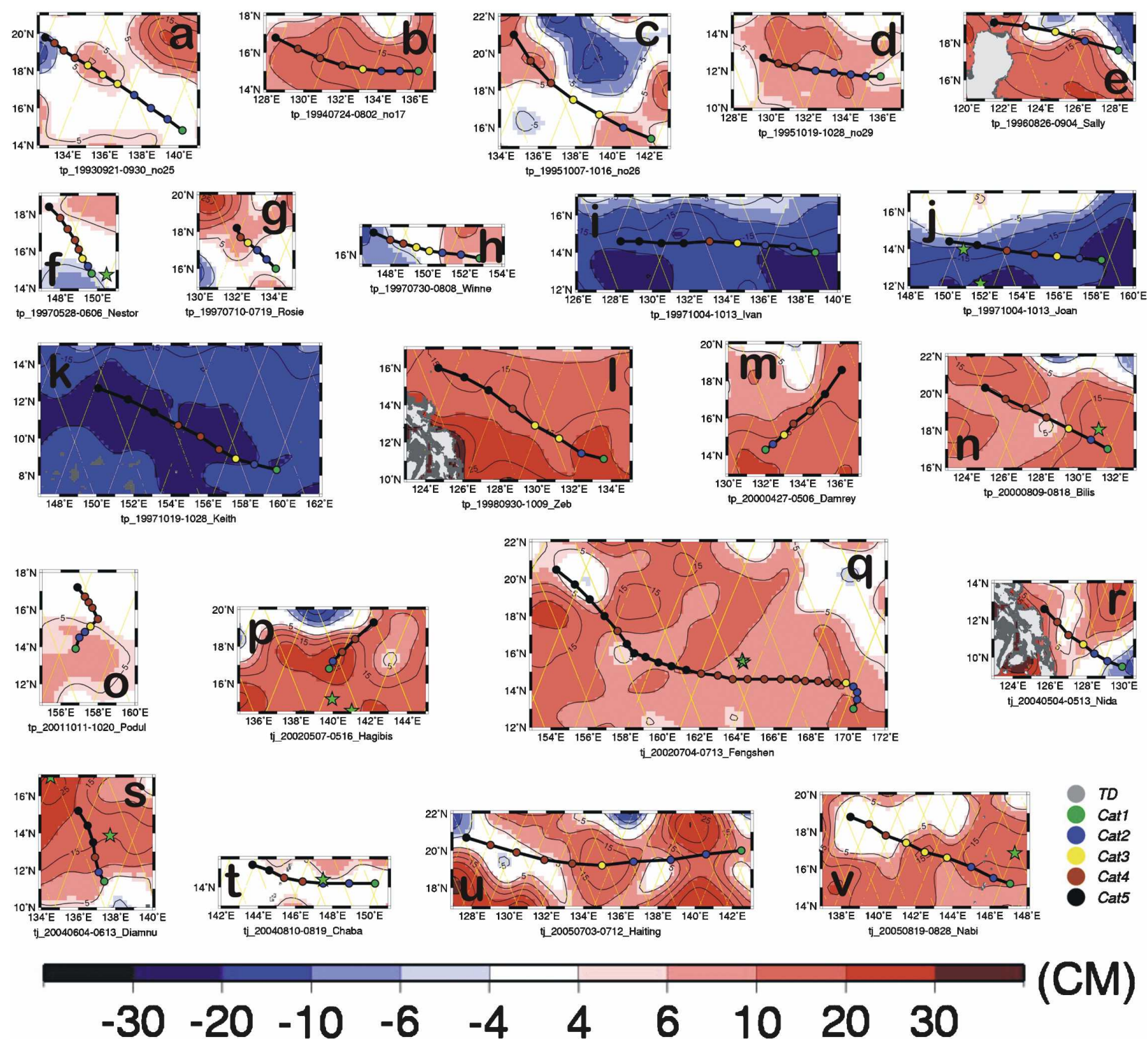

FIG. 8. Pretyphoon SSHA (cm) maps and the tracks of the 22 SEZ cases (in chronological order, see also Table 3). Locations of the in situ profiles are depicted as green stars. The altimetry tracks are depicted in yellow.

deep as $117 \mathrm{~m}$ and UOHC is as high as $112 \mathrm{~kJ} \mathrm{~cm}^{-2}$, self-induced cooling can already be well-constrained under the climatological condition (Fig. 10a), thus, only when $U_{h}=1$ and $2 \mathrm{~m} \mathrm{~s}^{-1}$ would the storm-induced SST cooling exceed the threshold. In Table 3 , it is seen that the observed translation speed is 3.0 and $6.4 \mathrm{~m} \mathrm{~s}^{-1}$ for the two normal cases (cases $f$ and $t$ ), suggesting the self-induced cooling will not exceed the threshold limit at these translation speeds.

\section{3) Positive-SSHA features}

Followed from above, one can see that in the gyre, the background climatological warm layer is already very deep, with D26 extends to around $108 \mathrm{~m}$ and UOHC to $90 \mathrm{~kJ} \mathrm{~cm}^{-2}$ (dashed gray profiles in Fig. 9c and Table 4c). Over the positive-SSHA features in the gyre region, the warm layer can extend even deeper, corresponding to D26 of an average of $134 \mathrm{~m}$ and UOHC of $122 \mathrm{~kJ} \mathrm{~cm}^{-2}$ (solid black profiles in Fig. 9c and Table 4c). Certainly under this situation, the corresponding storm-induced SST cooling is very limited, thus, only when $U_{h}=1 \mathrm{~m} \mathrm{~s}^{-1}$ would the storm-induced SST cooling exceed the threshold limit (Fig. 10d). As shown in Table 3, the observed translation speed of these cases ranges between 2.3 and $9.4 \mathrm{~m} \mathrm{~s}^{-1}$, confirming that the corresponding self-induced cooling of 

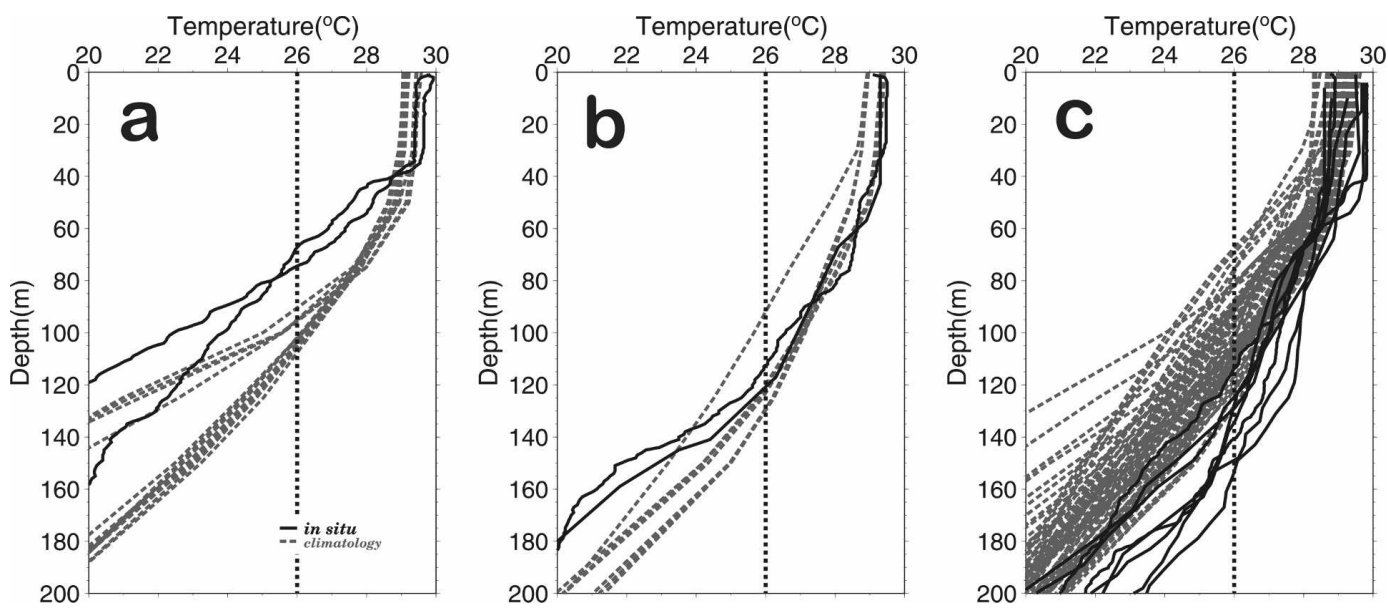

FIG. 9. In situ depth-temperature profiles (solid black) vs the background climatological profiles (dashed gray) for various scenarios in the gyre. (a) The negative-SSHA feature scenario. (b) The normal (no feature) scenario. (c) The positive-SSHA feature scenario. Locations of the in situ profiles are depicted as green stars in Fig. 8.

these storms would not have fallen below the threshold (Fig. 10d).

Comparing the findings in the gyre central and the SEZ, it is found that in the gyre central the background climatological warm layer is already very deep. Therefore the self-induced cooling negative feedback can be suppressed without encountering the positive features. Whereas in the SEZ situation, the background clima- tological warm layer is much shallower and encountering positive features is critical since the background climatological upper-ocean thermal structure could not have supported intensification to category 5 .

\section{c. The case in the Kuroshio region}

In Fig. 2b, one can see that the background climatological D26 in the Kuroshio region is around $50-80 \mathrm{~m}$

TABLE 4. Comparison of D26, UOHC, and SST between in situ profiles and the background climatology in the gyre for (a) negative-SSHA feature scenario, (b) normal (no feature scenario), and (c) positive-SSHA feature scenario.

\begin{tabular}{|c|c|c|c|c|c|c|c|c|c|c|}
\hline (a) & $\begin{array}{l}\text { In situ } \\
\text { profiles }\end{array}$ & $\begin{array}{c}\text { In situ } \\
\text { D26 (m) }\end{array}$ & $\begin{array}{c}\mathrm{D} 26(\mathrm{~m}) \\
\text { (climatology) }\end{array}$ & $\begin{array}{c}\Delta \mathrm{D} 26 \\
(\mathrm{~m})\end{array}$ & $\begin{array}{c}\text { In situ } \\
\text { UOHC } \\
\left(\mathrm{kJ} \mathrm{cm}^{-2}\right)\end{array}$ & $\begin{array}{c}\text { UOHC } \\
\text { (climatology) } \\
\left(\mathrm{kJ} \mathrm{cm}^{-2}\right)\end{array}$ & $\begin{array}{c}\Delta \mathrm{UOHC} \\
\left(\mathrm{kJ} \mathrm{cm}^{-2}\right)\end{array}$ & $\begin{array}{c}\text { In situ } \\
\text { SST }\left({ }^{\circ} \mathrm{C}\right)\end{array}$ & $\begin{array}{c}\mathrm{SST}\left({ }^{\circ} \mathrm{C}\right) \\
\text { (climatology) }\end{array}$ & $\begin{array}{c}\Delta \mathrm{SST} \\
\left({ }^{\circ} \mathrm{C}\right)\end{array}$ \\
\hline & Joan_1 & 74 & 105 & -31 & 82 & 101 & -19 & 29.8 & 29.1 & +0.7 \\
\hline & Joan_2 & 67 & 105 & -38 & 77 & 104 & -27 & 29.7 & 29.1 & +0.6 \\
\hline & Avg & 71 & 105 & -35 & 80 & 103 & -23 & 29.8 & 29.1 & +0.7 \\
\hline \multirow[t]{4}{*}{ (b) } & $\begin{array}{l}\text { In situ } \\
\text { profiles }\end{array}$ & $\begin{array}{c}\text { In situ } \\
\text { D26 (m) }\end{array}$ & $\begin{array}{c}\mathrm{D} 26(\mathrm{~m}) \\
\text { (climatology) }\end{array}$ & $\begin{array}{l}\Delta \mathrm{D} 26 \\
(\mathrm{~m})\end{array}$ & $\begin{array}{c}\text { In situ } \\
\text { UOHC } \\
\left(\mathrm{kJ} \mathrm{cm}^{-2}\right)\end{array}$ & $\begin{array}{c}\text { UOHC } \\
\text { (climatology) } \\
\left(\mathrm{kJ} \mathrm{cm}^{-2}\right)\end{array}$ & $\begin{array}{l}\Delta \mathrm{UOHC} \\
\left(\mathrm{kJ} \mathrm{cm}^{-2}\right)\end{array}$ & $\begin{array}{c}\text { In situ } \\
\operatorname{SST}\left({ }^{\circ} \mathrm{C}\right)\end{array}$ & $\begin{array}{c}\mathrm{SST}\left({ }^{\circ} \mathrm{C}\right) \\
\text { (climatology) }\end{array}$ & $\begin{array}{r}\Delta \mathrm{SST} \\
\left({ }^{\circ} \mathrm{C}\right)\end{array}$ \\
\hline & Chaba & 121 & 116 & +5 & 116 & 118 & -2 & 29.4 & 29.3 & +0.1 \\
\hline & Nestor & 113 & 118 & -5 & 115 & 105 & +10 & 29.1 & 29.1 & 0. \\
\hline & Avg & 117 & 117 & 0 & 116 & 112 & +4 & 29.3 & 29.2 & +0.1 \\
\hline (c) & $\begin{array}{l}\text { In situ } \\
\text { profiles }\end{array}$ & $\begin{array}{c}\text { In situ } \\
\text { D26 (m) }\end{array}$ & $\begin{array}{c}\mathrm{D} 26(\mathrm{~m}) \\
\text { (climatology) }\end{array}$ & $\begin{array}{l}\Delta \mathrm{D} 26 \\
(\mathrm{~m})\end{array}$ & $\begin{array}{c}\text { In situ } \\
\text { UOHC } \\
\left(\mathrm{kJ} \mathrm{cm}^{-2}\right)\end{array}$ & $\begin{array}{c}\text { UOHC } \\
\text { (climatology) } \\
\left(\mathrm{kJ} \mathrm{cm}^{-2}\right)\end{array}$ & $\begin{array}{l}\Delta \mathrm{UOHC} \\
\left(\mathrm{kJ} \mathrm{cm}^{-2}\right)\end{array}$ & $\begin{array}{c}\text { In situ } \\
\operatorname{SST}\left({ }^{\circ} \mathrm{C}\right)\end{array}$ & $\begin{array}{c}\mathrm{SST}\left({ }^{\circ} \mathrm{C}\right) \\
\text { (climatology) }\end{array}$ & $\begin{array}{r}\Delta \mathrm{SST} \\
\left({ }^{\circ} \mathrm{C}\right)\end{array}$ \\
\hline & Bilis & 114 & 90 & +24 & 122 & 83 & +39 & 29.8 & 29.2 & +0.6 \\
\hline & Hagibis_1 & 141 & 106 & +37 & 114 & 70 & +44 & 28.8 & 28.7 & +0.1 \\
\hline & Hagibis_2 & 153 & 106 & +49 & 131 & 70 & +61 & 28.6 & 28.7 & -0.1 \\
\hline & Fengshen_1 & 125 & 97 & +27 & 105 & 80 & +25 & 29.3 & 29.0 & +0.3 \\
\hline & Fengshen_2 & 129 & 97 & +31 & 104 & 80 & +24 & 28.8 & 29.0 & -0.2 \\
\hline & Dianmu_1 & 149 & 122 & +35 & 144 & 110 & +34 & 29.7 & 29.1 & +0.6 \\
\hline & Dianmu_2 & 128 & 122 & +14 & 128 & 110 & +18 & 29.5 & 29.1 & +0.4 \\
\hline & Nabi & 134 & 120 & +19 & 129 & 116 & +13 & 29.7 & 29.4 & +0.4 \\
\hline & Avg & 134 & 108 & +29 & 122 & 90 & +32 & 29.3 & 29.0 & +0.3 \\
\hline
\end{tabular}



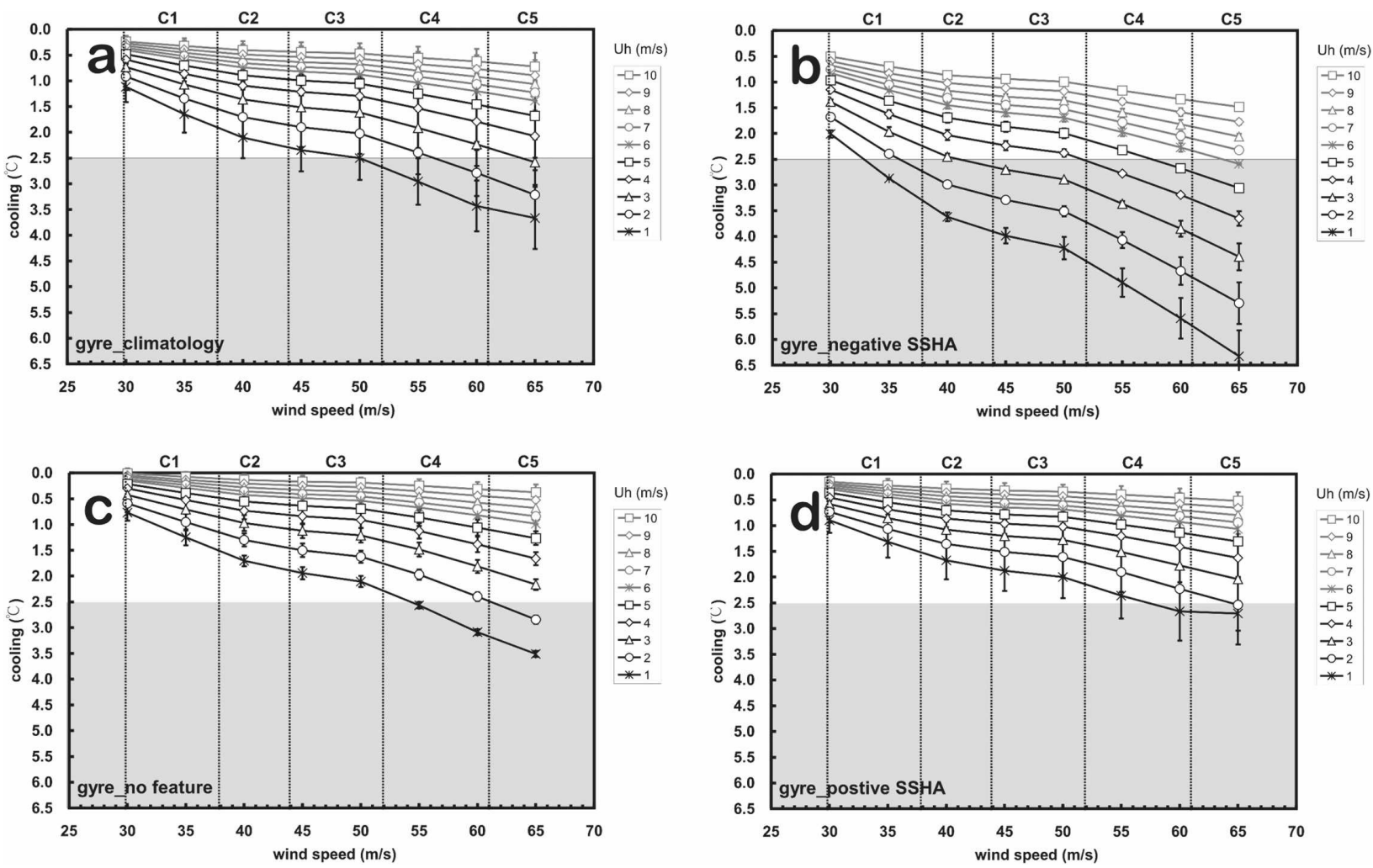

FIG. 10. As in Fig. 7, but for the self-induced ocean cooling estimation for the gyre cases. (a) Estimation based on the climatological profiles (dashed gray profiles in Fig. 9) along the typhoon tracks. (b) Estimation based on the in situ profiles (solid black profiles in Fig. 9a) inside the negative-SSHA features. (c) Estimation based on the in situ profiles (solid black profiles in Fig. 9b) under normal (no feature) condition. (d) Estimation based on the in situ profiles (solid black profiles in Fig. 9c) inside the positive-SSHA features.

(Fig. 2b), roughly in between the typical values at the SEZ and the gyre region. In the past 13 yr, 1 category 5 typhoon peaked in the Kuroshio region and it belongs to the positive-SSHA features scenario (Table 5, Fig. 11). In Fig. 11a, we see that typhoon Bart (1999) intensified all the way from category 1 to 5 on a prominent positive-SSHA feature (SSHA $\sim 20-40 \mathrm{~cm}$ ) when passing over the Kuroshio region. Because no in situ profile is found in this case, the observed SSHA information is added to a simple two-layer reduced-gravity ocean model $^{4}$ (Goni et al. 1996; Shay et al. 2000) to assess the

\footnotetext{
${ }^{4}$ At each location $(x, y)$ and time $(t)$, the observed satellite SSHA $\left(\eta^{\prime}\right)$ can be used to estimate the depth of the $20^{\circ} \mathrm{C}$ isotherm (D20 or $\left.h_{1}\right)$ as $h_{1}(x, y, t)=\overline{h_{1}}(x, y)+\left[\rho_{2}(x, y)\right] /\left[\rho_{2}(x, y)-\rho_{1}(x, y)\right]$ $\eta^{\prime}(x, y, t)$ [see Eq. (1)], where $\overline{h_{1}}$ is the mean climatological D20 and $\rho_{1}, \rho_{2}$ are the density (calculated from the NOAA/WOA01 temperature and salinity database; Millero et al. 1980; UNESCO 1983) of the two layers (i.e., from sea surface to D20 and from D20 the bottom of the ocean). After the D20 estimation, the depth of the $26^{\circ} \mathrm{C}$ isotherm (D26 or $\mathrm{H}$ ) is estimated based on the climatological ratio (Stephens et al. 2002) between D20 and D26 as $H(x, y, t)=\theta h_{1}(x, y, t)$ [see Eq. (2)], where $H$ represents D26 and $\theta$ is the climatological ratio. Thus, the difference between the
}

deepening impact of this positive-SSHA feature. The applicability of this model in the western North Pacific has been validated by Pun et al. (2007) using more than 5000 coincident and collocated in situ profiles from the Argo floats (Gould et al. 2004) and the NOAA/GTSPP database (Keeley et al. 2003). It can be seen that without the positive-SSHA feature, the climatological D26 is between 60 and $80 \mathrm{~m}$ (Fig. 11b), while with the positive-SSHA feature, the D26 extends to around $100 \mathrm{~m}$ (Fig. 11c), indicating the 30-m deepening (Fig. 11d).

Without the in situ profiles, the storm-induced SST cooling is only estimated using the climatological profiles (dashed gray profiles in Fig. 12a). In Fig. 12b, it is shown that because Bart travels very slowly at $U_{h}=1.9$ $\mathrm{m} \mathrm{s}^{-1}$ (Table 5), it is not possible to support intensification to the fifth category under the climatological condition, as the storm-induced SST cooling could already exceed the threshold of $2.5^{\circ} \mathrm{C}$ before Bart reaches the fifth category (i.e., at the third and fourth

estimated and the climatological D20 and D26 is due to the deepening (or shoaling) by positive (or negative) SSHA features (Goni et al. 1996; Shay et al. 2000). 
TABLE 5. The Kuroshio case and the primary feature encountered during intensification. The intensification period and the average translation speed $\left(U_{h}\right)$ when passing over the feature are also summarized.

\begin{tabular}{lccccc}
\hline \hline Typhoon & Month and year & Intensification period & Primary feature & Altimetry cycle & $U_{h}(\mathrm{~m})$ \\
\hline a. Bart & Sep 1999 & 1200 UTC 20-0600 UTC 22 Sep & + & 9 Sep-18 Sep & 1.9 \\
\hline
\end{tabular}

categories). This suggests that passing over the observed positive-SSHA feature is critical to support Bart's intensification to the fifth category, given that the climatological UOTS could not provide the support its intensification to the fifth category

\section{Discussion}

a. Issue on the percentage of category 5 typhoons that require encountering positive-SSHA features during 1993-2005

From section 4, one sees that the situation in the SEZ and Kuroshio region is different from the gyre central situation. In the gyre central region, the background climatological warm layer is already deep enough (D26 $\sim 105-117 \mathrm{~m}$ and $\mathrm{UOHC} \sim 80-122 \mathrm{~kJ} \mathrm{~cm}^{-2}$ ) to restrain the storm's self-induced ocean cooling, given the observed translation speeds (Table 3). Therefore passing over the positive SSHA features is not critical and storms are observed to intensify to category 5 without encountering any features or even on negative-SSHA features.

However, in the SEZ and the Kuroshio cases, it is critical for these storms to pass over the observed positive-SSHA features because the background climatological warm layer is relatively shallow (D26 $\sim 60 \mathrm{~m}$ and $\mathrm{UOHC} \sim 50 \mathrm{~kJ} \mathrm{~cm}^{-2}$, Table 2). It is found that given the observed translation speeds (Tables 1 and 5), it is not possible to limit the self-induced cooling negative feedback with the climatological upper-ocean thermal structure. As the ocean plays a necessary role in intensification (Holliday and Thompson 1979; Emanuel 1986), these cases could not have reached category 5 without keeping the self-induced cooling restrained. In the presence of positive features, the warm layer in this relatively shallow background can be effectively deepened by nearly $100 \%$ (D26 $103 \mathrm{~m}$ and UOHC $\sim 109$ $\mathrm{kJ} \mathrm{cm}^{-2}$; Table 2). This enables the self-induced cooling negative feedback to be limited to support intensification. As such, these positive-SSHA features can be regarded as "boosters" because their presence enables a typhoon to meet the ocean's condition in a shallow background. From section 4, it can be seen that in the 13 yr during 1993-2005, 8 (i.e., 7 SEZ and 1 Kuroshio) out of the 30 category 5 storms belong to this situation. In other words, without encountering the positiveSSHA ocean features (i.e., boosters), 27\% (8/30) of the storms could not have satisfied the ocean's part of the necessary condition for reaching the category 5 intensity.

Also, it should be clarified that this does not suggest that the other parameters (e.g., atmospheric wind shear and storm structure) are not important in intensification to category 5 . Certainly to reach category 5 , all related atmospheric, ocean, and storm conditions need to be favorable. The focus of this study is to show whether or not encountering ocean features are required to meet the ocean's part of the necessary condition. Because the ocean is a necessary condition in intensification, even if all other conditions are met but without meeting one necessary condition, a storm could still not intensify to category 5 .

\section{b. Issue on the choice of the $2.5^{\circ} \mathrm{C}$ threshold for self-induced cooling and enthalpy flux}

In this work, the $2.5^{\circ} \mathrm{C}$ threshold proposed by Emanuel (1999) and Emanuel et al. (2004) is adopted to indicate unfavorable condition for intensification. From Emanuel (1999), this amount of cooling is sufficient to shut down the entire energy production of a storm. To further substantiate this, we calculate the corresponding air-sea sensible $\left(Q_{S}\right)$ and latent heat fluxes $\left(Q_{L}\right)$ using the bulk aerodynamic formulas (Jacob et al. 2000; Cione and Uhlhorn 2003; Powell et al. 2003; Black et al. 2007) as follows:

$$
\begin{aligned}
Q_{S} & =C_{H} W\left(T_{s}-T_{a}\right) \rho_{a} C_{p a} \\
\text { and } \quad Q_{L} & =C_{E} W\left(q_{s}-q_{a}\right) \rho_{a} L_{v a},
\end{aligned}
$$

where $C_{H}$ and $C_{E}$ are the sensible and the latent heat (moisture) exchange coefficients, respectively; $W$ is the wind speed; $T_{s}$ and $T_{a}$ represent SST and near surface air temperature, respectively; $q_{s}$ and $q_{a}$ represent surface and air specific humidity, respectively; and $\rho_{a}, C_{p a}$, and $L_{v a}$ are air density, heat capacity of the air, and latent heat of vaporization, respectively. In this work, the exchange coefficients are from Black et al. (2007), wind speed is from the JTWC's best-track data, the near-surface atmospheric data is from the $1.125^{\circ}$ resolution data the 40-yr European Centre for MediumRange Weather Forecasts (ECMWF) Re-Analysis (ERA-40), and the SST data is from the output of the mixed layer model (i.e., with incorporation of the selfinduced cooling effect). 

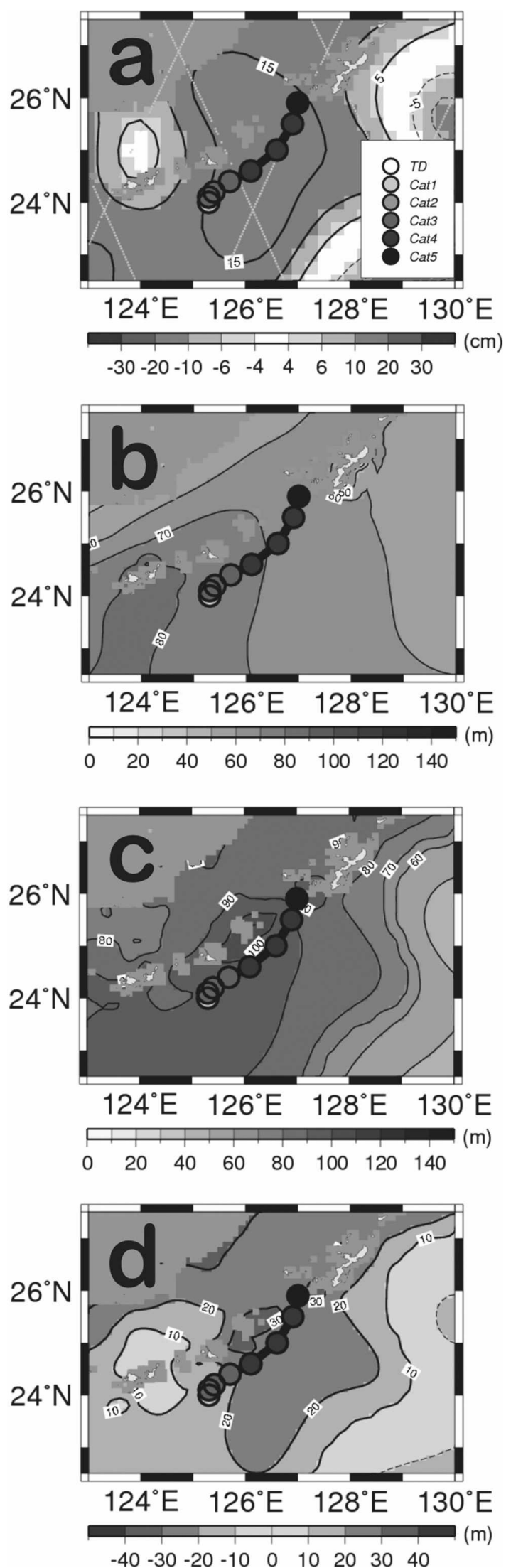

As the flux calculation requires multiple input datasets (e.g., ECMWF atmospheric data and in situ UOTS profiles for the mixed layer model), we were able to calculate the sensible and latent heat fluxes for seven cases during 2001-05. Among them, two cases belong to the SEZ/positive-SSHA feature scenario [i.e., Maemi (2003) and Maon (2004)], one case belongs to the gyre/normal scenario [i.e., Chaba (2004)], and four cases belong to the gyre/positive-SSHA feature scenario [i.e., Hagibis (2002), Fengshen (2002), Dianmu (2004), and Nabi (2005)]. For each case, sensible and latent heat fluxes are estimated under the in situ (i.e., with features) and the climatological condition.

Figure 13 depicts the average available enthalpy (sensible plus latent heat fluxes) under the different conditions. It can be seen that the flux condition also suggests that under the SEZ_climatological condition (dashed gray curve with triangles), there will not be sufficient energy to support intensification to category 5. As in Fig. 13, the average enthalpy reaches zero at categories 3 and 4, showing unfavorable condition for continual intensification to category 5. However, if it encounters positive-SSHA feature in the SEZ (i.e., solid gray curve with diamonds), the available enthalpy supply increases significantly. One can see that the available enthalpy increases during the intensification process (e.g., more than $1000 \mathrm{~W} \mathrm{~m}^{-2}$ is available at category 4), showing favorable condition for continual intensification to category 5 .

The flux situation in the gyre central also concurs with the findings in section 4 that in the gyre central region, even without encountering positive-SSHA features, the background climatology can also provide sufficient energy for intensification. One can see in Fig. 13 that the available enthalpy condition is around $1000 \mathrm{~W}$ $\mathrm{m}^{-2}$ at category 3 and around $1300 \mathrm{~W} \mathrm{~m}^{-2}$ at category 4 for the gyre climatology (dashed black curve with triangles) and the gyre neutral (i.e., thin black curve with bullets) conditions.

\section{c. Issue on $1 D$ versus $3 D$ ocean simulations}

Finally, as the 1D mixed layer model (Price et al. 1986) is a simple ocean model and does not account for

$\leftarrow$

FIG. 11. The Kuroshio positive-SSHA feature case [i.e., Bart (1999), see also Table 5]. (a) Pretyphoon SSHA (cm) map and the TC track. The altimetry tracks are depicted as dotted lines. (b) The background climatological D26 from the WOA01 (Stephens et al. 2002). (c) The positive-feature modulated D26, as estimated from a two-layer reduced gravity ocean model proposed by Goni et al. (1996) and Shay et al. (2000). (d) The deepening of D26 by the positive SSHA feature [i.e., (c)] as compared with climatology [i.e., (b)]. 

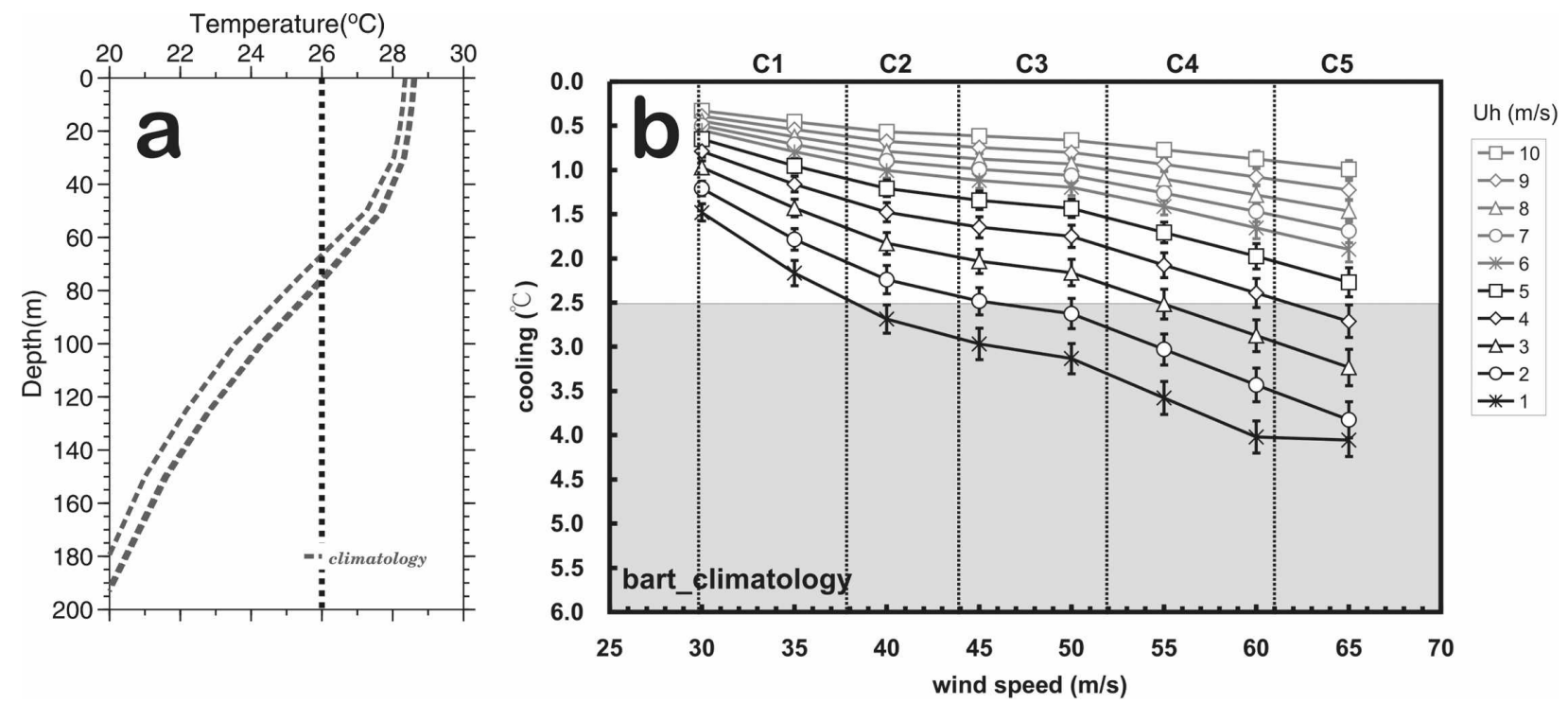

FIG. 12. (a) Climatological depth-temperature profiles along the track of typhoon Bart (1999). (b) As in Fig. 7, but for the self-induced ocean cooling estimation using the climatological profiles in (a).

the possible lateral transport associated with the ocean eddies (Jacob et al. 2000; Jacob and Shay 2003), a full $3 \mathrm{D}$ ocean model is used to assess the possible difference. The model used is the EASNFS model from the U.S. Naval Research Laboratory (Ko et al. 2003; Chap- man et al. 2004). It is an experimental real-time Ocean Nowcast/Forecast System for the East Asian Seas. The model domain covers $17.3^{\circ} \mathrm{S}-52.2^{\circ} \mathrm{N}$ and $99.2^{\circ}-158.2^{\circ} \mathrm{E}$. The system produces nowcast for the sea level variation, 3D ocean current, temperature, and salinity fields.

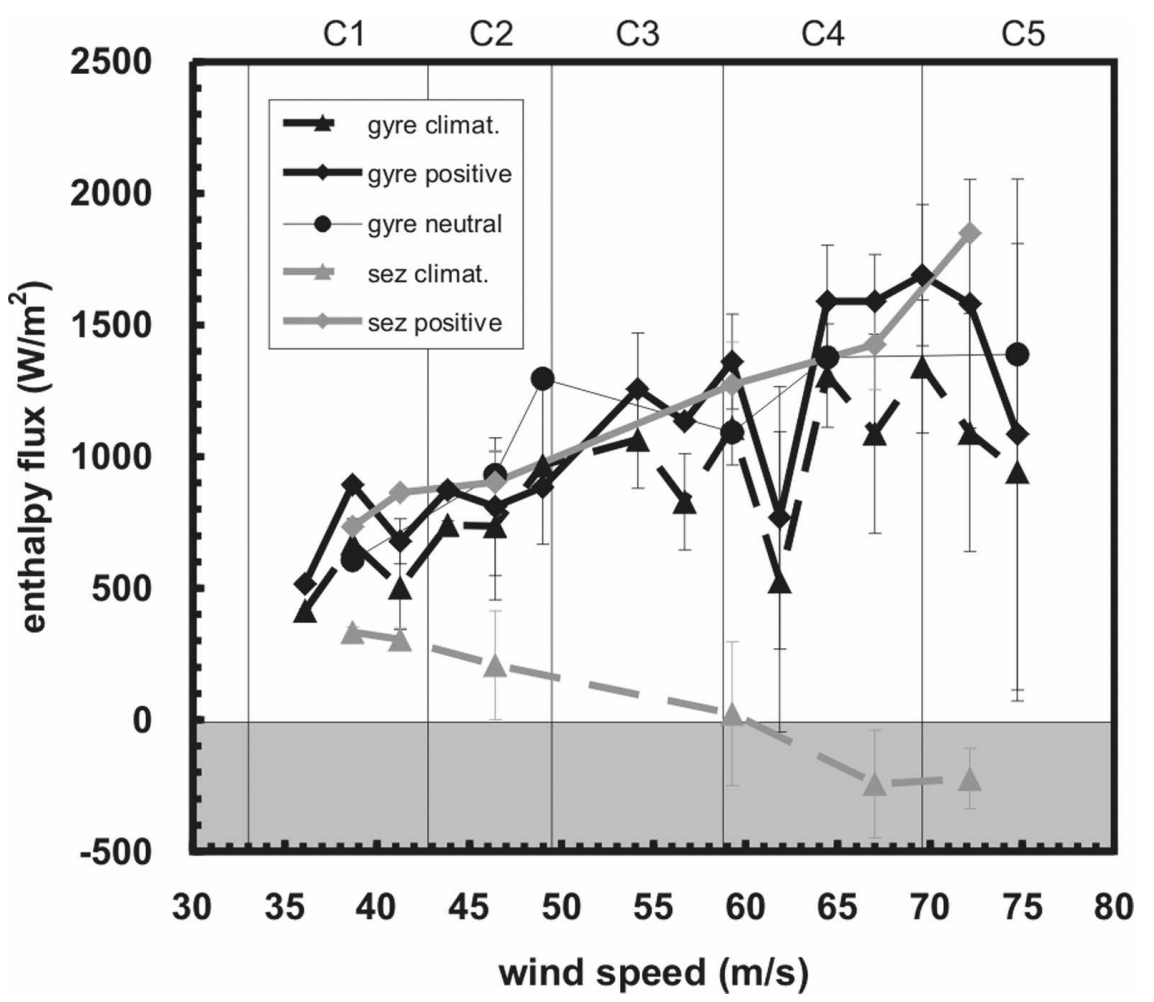

FIG. 13. The estimated available enthalpy (sensible + latent heat flux) during various stages of intensification for different scenarios. 

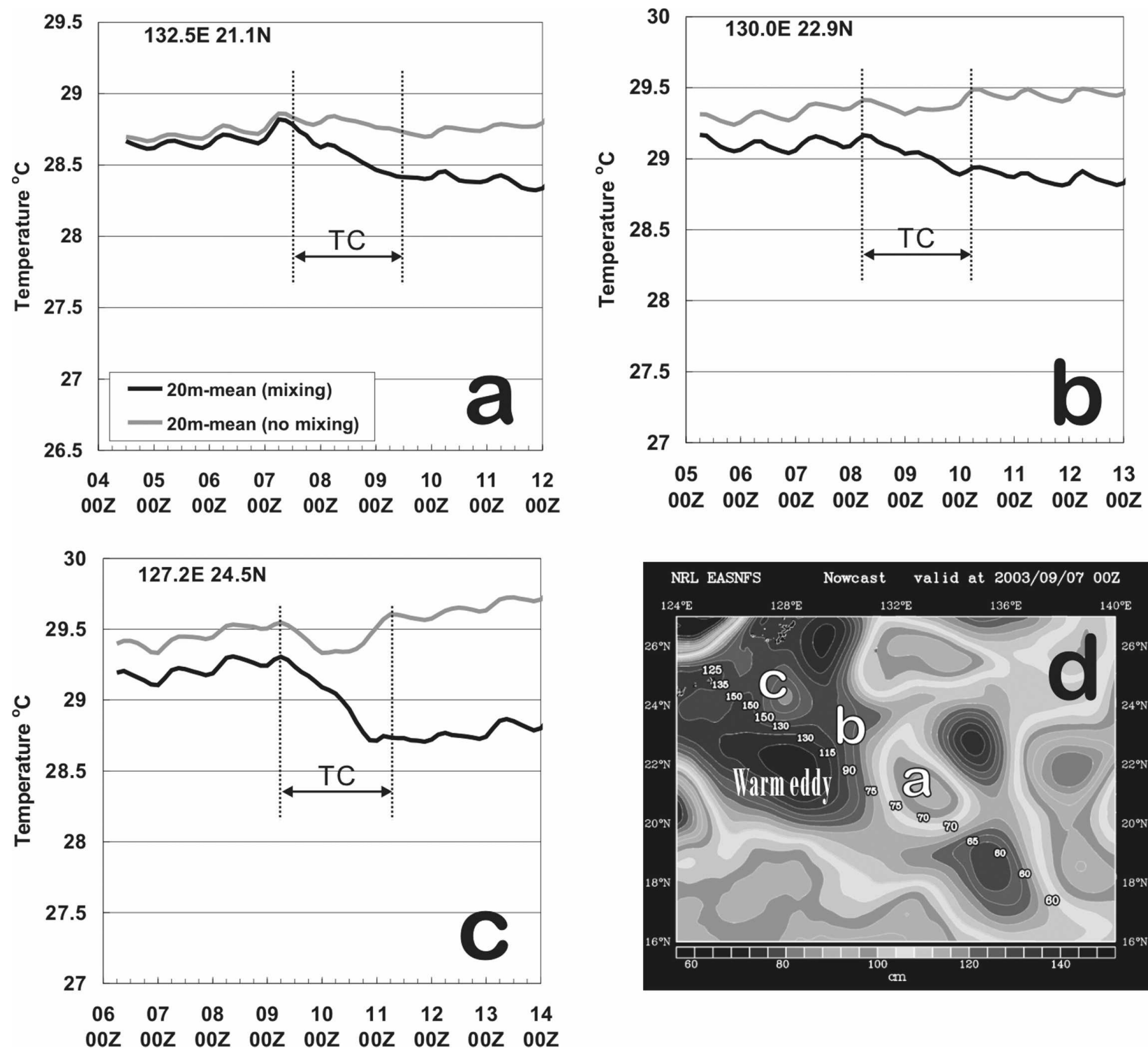

FIG. 14. 3D numerical experiments using the US NRL's EASNFS ocean model showing upper-ocean temperature evolution (average from surface to 20-m depth) before, during, and after typhoon's passing for three locations. (d) Points b and c are located in the warm eddy while point a is the location outside of the eddy. For each point, the simulation is done with mixing (black curves) and without mixing (gray curves).

EASNFS is a 41-level sigma-z data-assimilating ocean model and the spatial resolution is $1 / 16^{\circ}$. Real-time satellite altimetry sea surface height anomaly data (e.g., TOPEX/Poseidon and Jason-1) and SST [e.g., the NOAA Advanced Very High Resolution Radiometer (AVHRR)] are assimilated to produce realistic nowcast of the ocean condition in the western North Pacific. Three-hourly surface heat fluxes, solar radiation, wind stresses, and sea level air pressure from NRL's Navy Operational Global Atmospheric Prediction System (NOGAPS) system are used for surface forcing.

In this work, the $3 \mathrm{D}$ simulation is performed on the case of supertyphoon Maemi (2003) (Lin et al. 2005) as the ocean eddy associated with this case is the largest in the eddy rich zone (i.e., SEZ, see Fig. 5f). In the simulations, two experiments are run, one is the full simulation (i.e., including both $1 \mathrm{D}$ mixing and lateral effects) and the other is the no-mixing run (i.e., switching off the 1D mixing component). Figure 14 depicts the simulation results for three locations where points $b$ and c represent the "inside eddy" condition and point a represent the "outside eddy" condition (Fig. 14d). From Figs. 14b,c, one can see that in the no-mixing runs (gray curves), there is little difference before and after 
typhoon's passing. Only with the inclusion of the 1D mixing effect (black curves) can the cooling effect induced by typhoon's forcing be seen. As in Fig. 14a, a similar situation is found in the outside region. These results support previous reports that the 1D mixing effect is the primary mechanism in cyclone's self-induced cooling and it is applicable to use the 1D mixed layer model to assess the self-induced cooling in this work (Price 1981; Gallacher et al. 1989; Emanuel 1999; Jacob et al. 2000; Jacob and Shay 2003; Emanuel et al. 2004).

\section{Conclusions}

There is much interest to study the role that ocean features play in the intensification of category 5 typhoons. Based on the in situ upper-ocean thermal structure profiles, satellite altimetry, and the SST data, JTWC's best-track typhoon data, climatological ocean thermal structure data, and an ocean mixed layer model, this work systematically studies the role that ocean features play in the 30 western North Pacific category 5 typhoons occurring during the May-October typhoon season in 1993-2005.

It is found that the background climatological upperocean thermal structure is an important factor in determining the criticalness of feature encountering. If the background climatological warm layer is already deep enough, for example, in the gyre central region where $\mathrm{D} 26 \sim 110 \mathrm{~m}$ and $\mathrm{UOHC} \sim 100 \mathrm{~kJ} \mathrm{~cm}^{-2}$, then passing over the positive SSHA features is not critical because the background itself can already effectively restrain the negative feedback to intensity from cyclone's selfinduced ocean cooling. In the gyre central region, typhoons are found to intensify to category 5 not only over positive SSHA features, but also without encountering features, or even when passing over negative SSHA features.

However, in the relatively shallow background, for example in the SEZ and the Kuroshio regions where $\mathrm{D} 26 \sim 60 \mathrm{~m}$ and $\mathrm{UOHC} \sim 50 \mathrm{~kJ} \mathrm{~cm}^{-2}$, passing over positive SSHA features is critical in order to meet the ocean's part of necessary condition in intensification. It is found that without the deepening of the warm layer by the features, it is not possible to restrain the selfinduced cooling negative feedback to support intensification as there will not be sufficient sensible and latent heat fluxes available. In the past $13 \mathrm{yr}$, all 8 cases passed through these 2 regions belong to this situation.

Finally, it should be clarified that certainly to reach the category 5 intensity, a full suite of necessary conditions (e.g., atmospheric vertical wind shear and storm structure conditions) all need to be met (Gray 1979; Holliday and Thompson 1979; Emanuel et al. 2004;
Houze et al. 2007). The focus of this work is to discuss whether it is critical to encounter ocean features to meet the ocean's part of necessary condition in intensification. It does not imply that other necessary conditions are not important in intensification. Followed from this work, in the Part II of the series, issues regarding the ocean's thermal structure with the cyclone's translation speed for the western North Pacific category 5 typhoons will be addressed.

Acknowledgments. The authors thank Dr. Colin Stark for his helpful comments and Prof. Dong-Ping Wang for providing the mixed layer model and helpful discussions. Thanks also to NASA, Remote Sensing Systems, Argo in situ ocean float team, and the Joint Typhoon Warning Center for data provision. This work is supported by the National Science Council, Taiwan through Grants NSC95-2611-M-002-024-MY3, NSC972111-M-002-014-MY3, and NTU-97R0302. This work is also a collaborative effort between Taiwan National Science Council's Integrated Typhoon-Ocean Program (ITOP) and the US Office of Naval Research's Typhoon DRI program.

\section{REFERENCES}

Bender, M. A., and I. Ginis, 2000: Real-case simulations of hurricane-ocean interaction using a high-resolution coupled model: Effects on hurricane intensity. Mon. Wea. Rev., 128, 917-946.

Black, P. G., and Coauthors, 2007: Air-sea exchange in hurricanes. Bull. Amer. Meteor. Soc., 88, 357-374.

Chapman, D. C., D. S. Ko, and R. H. Preller, 2004: A highresolution numerical modeling study of the subtidal circulation in the Northern South China Sea. IEEE J. Oceanic Eng., 29 (4), 1087-1104.

Cione, J. J., and E. W. Uhlhorn, 2003: Sea surface temperature variability in hurricanes: Implications with respect to intensity change. Mon. Wea. Rev., 131, 1783-1796.

Emanuel, K. A., 1986: An air-sea interaction theory for tropical cyclones. Part I: Steady-state maintenance. J. Atmos. Sci., 43, 585-605.

_ 1999: Thermodynamic control of hurricane intensity. $\mathrm{Na}$ ture, 401, 665-669.

_ 2000: A statistical analysis of tropical cyclone intensity. Mon. Wea. Rev., 128, 1139-1152.

_, 2006 : Climate and tropical cyclone activity: A new model downscaling approach. J. Climate, 19, 4797-4802.

— C. CesAutels, C. Holloway, and R. Korty, 2004: Environmental control of tropical cyclone intensity. J. Atmos. Sci., 61, 843-858.

Fu, L. L., E. J. Christensen, C. A. Yamarone, M. Lefebvre, Y. Menard, M. Dorrer, and P. Escudier, 1994: TOPEX/ POSEIDON Mission Overview. J. Geophys. Res., 99, 24 36924381.

Gallacher, P. C., R. Rotunno, and K. A. Emanuel, 1989: Tropical cyclogenesis in a coupled ocean-atmosphere model. Preprints, 18th Conf. on Hurricanes and Tropical Meteorology, San Diego, CA, Amer. Meteor. Soc., 121-122. 
Goni, G. J., and J. A. Trinanes, 2003: Ocean thermal structure monitoring could aid in the intensity forecast of tropical cyclones. Eos, Trans. Amer. Geophys. Union, 84, 573-580.

— S. Kamholtz, S. Garzoli, and D. B. Olson, 1996: Dynamics of the Brazil-Malvinas confluence based upon inverted echo sounders and altimetry. J. Geophys. Res., 101, 16 273-16 289.

Gould, J., and Coauthors, 2004: Argo profiling floats bring new era of in situ ocean observations. Eos, Trans. Amer. Geophys. Union, 85, 179, 190-191.

Gray, W. M., 1979: Hurricanes: Their formation, structure and likely role in the tropical circulation. Meteorology over the Tropical Oceans, D. B. Shaw, Ed., Royal Meteorological Society, 155-218.

Holliday, C. R., and A. H. Thompson, 1979: Climatological characteristics of rapidly intensifying typhoons. Mon. Wea. Rev., 107, 1022-1034.

Houze, R. A., Jr., S. S. Chen, B. F. Smull, W. C. Lee, and M. M. Bell, 2007: Hurricane intensity and eyewall replacement. Science, 315, 1235-1239.

Hwang, C., C. R. Wu, and R. Kao, 2004: TOPEX/Poseidon observations of mesoscale eddies over the subtropical countercurrent: Kinematic characteristics of an anticyclonic eddy and of a cyclonic eddy. J. Geophys. Res., 109, C08013, doi:10.1029/ 2003JC002026.

Jacob, S. D., and L. K. Shay, 2003: The role of oceanic mesoscale features on the tropical-cyclone induced mixed layer response. J. Phys. Oceanogr., 33, 649-676.

,-- A. J. Mariano, and P. G. Black, 2000: The 3D oceanic mixed layer response to hurricane Gilbert. J. Phys. Oceanogr., 30, 1407-1429.

Johnson, G. C., M. J. McPhaden, G. D. Rowe, and K. E. McTaggert, 2000: Upper equatorial Pacific Ocean current and salinity variability during the 1996-1998 El Niño-La Niña cycle. $J$. Geophys. Res., 105, 1037-1053.

Kaplan, J., and M. DeMaria, 2003: Large-scale characteristics of rapidly intensifying tropical cyclones in the North Atlantic basin. Wea. Forecasting, 18, 1093-1108.

Keeley, B., C. Sun, and L. P. Villeon, 2003: Global temperature and salinity profile program annual report. NOAA/National Oceanographic Data Center, Silver Spring, MD, $32 \mathrm{pp}$.

Ko, D. S., R. H. Preller, G. A. Jacobs, T. Y. Tang, and S. F. Lin, 2003: Transport reversals at Taiwan Strait during October and November 1999. J. Geophys. Res., 108, 3370, doi:10.1029/ 2003JC001836.

Leipper, D., and D. Volgenau, 1972: Hurricane heat potential of the Gulf of Mexico. J. Phys. Oceanogr., 2, 218-224.

Lin, I-I, W. T. Liu, C. C. Wu, J. C. H. Chiang, and C. H. Sui, 2003a: Satellite observations of modulation of surface winds by typhoon-induced upper ocean cooling. Geophys. Res. Lett., 30, 1131, doi:10.1029/2002GL015674.

— , and Coauthors, 2003b: New evidence for enhanced ocean primary production triggered by tropical cyclone. Geophys. Res. Lett., 30, 1718, doi:10.1029/2003GL017141.

— C. C. Wu, K. A. Emanuel, I. H. Lee, C. R. Wu, and I. F. Pun, 2005: The interaction of Supertyphoon Maemi (2003) with a warm ocean eddy. Mon. Wea. Rev., 133, 2635-2649.

Liu, K. S., and J. C. L. Chan, 1999: Size of tropical cyclones as inferred from ERS-1 and ERS-2 data. Mon. Wea. Rev., 127, 2992-3001.

Merrill, R. T., 1984: Structure of the tropical cyclone outflow layer. Preprints, 15th Conf. on Hurricanes and Tropical Meteorology, Miami, FL, Amer. Meteor. Soc., 421-426.

Millero, F. J., C. T. Chen, A. Bradshaw, and K. Schleicher, 1980:
A new high pressure equation of state for seawater. Deep-Sea Res., 27A, 255-264.

Oey, L. Y., T. Ezer, D.-P. Wang, S.-J. Fan, and X.-Q. Yin, 2006: Loop Current warming by Hurricane Wilma. Geophys. Res. Lett., 33, L08613, doi:10.1029/2006GL025873.

Philander, S. G. H., 1990: El Niño, La Niña, and Southern Oscillation. Academic Press, 293 pp.

Pickard, G. L., and W. J. Emery, 1990: Descriptive Physical Oceanography. Pergamon Press, 320 pp.

Powell, M. D., P. J. Vickery, and T. A. Reinhold, 2003: Reduced drag coefficient for high wind speeds in tropical cyclones. Nature, 422, 279-283.

Price, J. F., 1981: Upper ocean response to a hurricane. J. Phys. Oceanogr., 11, 153-175.

-, R. A. Weller, and R. Pinkel, 1986: Diurnal cycling: Observations and models of the upper ocean response to diurnal heating, cooling, and wind mixing. J. Geophys. Res., 91, 84118427.

Pun, I. F., I-I Lin, C. R. Wu, D. S. Ko, and W. T. Liu, 2007: Validation and application of altimetry-derived upper ocean thermal structure in the Western North Pacific Ocean for typhoon intensity forecast. IEEE Trans. Geosci. Remote Sens., 45 (6), 1616-1630.

Qiu, B., 1999: Seasonal eddy field modulation of the North Pacific Subtropical Countercurrent: TOPEX/Poseidon observations and theory. J. Phys. Oceanogr., 29, 1670-1685.

Richard, H. B., 1981: Gulf stream cold-core rings: Their physics, chemistry, and biology. Science, 212, 1091-1100.

Roemmich, D., and J. Gilson, 2001: Eddy transport of heat and thermocline waters in the North Pacific: A key to interannual/decadal climate variability? J. Phys. Oceanogr., 31, 675687.

Scharroo, R., W. H. F. Smith, and J. L. Lillibridge, 2005: Satellite altimetry and the intensification of Hurricane Katrina. Eos, Trans. Amer. Geophys. Union, 86, 366-367.

Shay, L. K., G. J. Goni, and P. G. Black, 2000: Effects of a warm oceanic feature on Hurricane Opal. Mon. Wea. Rev., 128, 1366-1383.

Stephens, C., J. I. Antonov, T. P. Boyer, M. E. Conkright, R. A. Locarnini, T. D. O'Brien, and H. E. Garcia, 2002: Temperature. Vol. 1, World Ocean Atlas 2001, NOAA Atlas NESDIS 49, $167 \mathrm{pp}$.

UNESCO, 1983: Algorithms for computation of fundamental properties of seawater. Unesco Tech. Paper in Marine Science $44,53 \mathrm{pp}$.

Wada, A., and N. Usui, 2007: Importance of tropical cyclone heat potential for tropical cyclone intensity and intensification in the Western North Pacific. J. Oceanogr., 63, 427-447.

Wang, Y., and C. C. Wu, 2003: Current understanding of tropical cyclone structure and intensity changes-A review. Meteor. Atmos. Phys., 87, 257-278, doi:10.1007/s00703-003-0055-6.

Wentz, F. J., C. Gentemann, D. Smith, and D. Chelton, 2000: Satellite measurements of sea surface temperature through clouds. Science, 288 (5467), 847-850.

Wu, C. C., C. Y. Lee, and I-I Lin, 2007: The effect of the ocean eddy on tropical cyclone intensity. J. Atmos. Sci., 64, 35623578.

Wyrtki, K., 1979: The response of sea surface topography to the 1976 El Niño. J. Phys. Oceanogr., 9, 1223-1231.

Yasuda, I., K. Okuda, and M. Hirai, 1992: Evolution of a Kuroshio warm-core ring-Variability of the hydrographic structure. Deep-Sea Res., 39, 131-161. 